\title{
Removal of fluoride from polluted waters using active carbon derived from barks of Vitex negundo plant
}

\author{
Mekala Suneetha', Bethanabhatla Syama Sundar ${ }^{1}$ and Kunta Ravindhranath ${ }^{2 *}$
}

\begin{abstract}
Background: Deleterious effects of fluoride contamination in ground waters on the health of human beings are well known and intensive research on developing de-fluoridation methods is globally pursued. Of the various methodologies, increasing interest is being envisaged in using the adsorption methods based on active carbons derived from plant material. In the present investigation, Nitric acid activated carbon derived from barks of Vitex negundo plant (NVNC) is probed for its de-fluoridation abilities.
\end{abstract}

Methods: The activated carbon is characterized adopting various physicochemical methods and surface morphological studies are carried out using FT-IR and SEM-EDX techniques. The effect of various parameters such as $\mathrm{pH}$, sorbent dosage, agitation time, initial concentration of fluoride, temperature, particle size and presence of foreign ions on the extraction of the fluoride is studied adopting Batch methods. The adsorption process is analyzed with Freundlich, Langmuir, Temkin and Dubinin-Radushkevich (D-R) isotherms and kinetics of adsorption is studied using pseudo first-order, pseudo second-order, Weber and Morris intraparticle diffusion, Bangham's pore diffusion and Elovich equations. The methodology developed is applied to real ground water samples.

Results: De-fluoridation is maximum at the $\mathrm{pH}$ : 7.0, adsorbent dosage: 4.0g/lit; equilibrium time: 50 min, Particle size: $45 \mu$ and temperature: $30 \pm 1^{\circ} \mathrm{C}$. The correlation coefficient values for the adsorption isotherms: Freundlich, Langmuir, Temkin and Dubinin-Radushkevich are $0.929,0.998,0.980$ and 0.946 respectively and for kinetic models: pseudo-first-order, pseudo-second-order, Weber and Morris intraparticle diffusion, Bangham's pore diffusion and Elovich equations are $0.989,0.994,0.874,0.902$ and 0.912 respectively. The Temkin heat of sorption, $\mathrm{B}$, and the Dubinin-Radushkevich mean free energy, E, for the activated carbon adsorbent are $0.196 \mathrm{~J} / \mathrm{mol}$ and $7.07 \mathrm{~kJ} / \mathrm{mol}$ respectively.

Conclusions: Nitric acid activated carbon derived from barks of Vitex negundo (NVNC) plant is found to be an effective adsorbent for the de-fluoridation of waters. The adsorption process is satisfactorily fitted with Langmuir adsorption isotherm with good correlation coefficient value and it indicates monolayer adsorption. The adsorption kinetics is found to follow pseudo-second-order kinetics. The Dubinin-Radushkevich mean free energy and Temkin heat of sorption confirm the physisorption nature as these are lower than $20 \mathrm{~kJ} / \mathrm{mol}$. The procedure developed is remarkably successful in de-fluoridation of real ground water samples.

Keywords: Fluoride removal; Batch adsorption technique; Inexpensive adsorbents; Surface characterization; Adsorption isotherms; Kinetic models; Applications

\footnotetext{
* Correspondence: ravindhranath.kunta@gmail.com

²Department of Chemistry, K L University, Vaddeswaram, 522502 Guntur Dt., AP, India

Full list of author information is available at the end of the article
} 


\section{Introduction}

Fluoride in drinking water has both beneficial and harmful effects on human health (Maheshwari and Meenakshi 2006). Though fluoride in minute amounts is an essential component for bones and for the formation of dental enamel in animals and humans (Grynpas et al. 2000; Jackson et al. 1973; Fawell et al. 2006; Kumar and Moss 2008; Underwood 1997), its high concentration cause irreversible demineralization of bones and tooth tissues which is known as dental and skeletal fluorosis, damage to the brain, liver, and kidney, headache, skin rashes, bone cancer, and even death in extreme cases (Susheela 2001; Barbier et al. 2010; Gazzano et al. 2010; Ayoob and Gupta 2006; Chaturvedi et al. 1990; Wang and Reardon 2001; Lounici et al. 1997; Srimurali et al. 1998; Savinelli and Black 1958; Ganvir and Das 2011; Chinoy 1991). The maximum permissible limit of fluoride in water is $1.5 \mathrm{mg} / \mathrm{l}$ as per WHO standards (WHO 1984, 2004; BIS 1991).

A variety of treatment procedures have been reported for the removal of excess fluoride from polluted waters based on precipitation (Aldaco et al. 2007; Akbar et al. 2008; Reardon and Wang 2000; Cengeloglu et al. 2002; Yadav et al. 2006; Nawlakhe et al. 1975; Saha 1993), ion exchange (Meenakshi and Viswanathan 2007; Castel et al. 2000; Feng Shen et al. 2003; Chubar et al. 2005; Apambire et al. 1997; Singh et al. 1999), reverse osmosis (Sehn 2008; Simons 1993), Donnan dialysis (Tor 2007; Garmes et al. 2002; Hichour et al. 1999), electrodialysis (Lahnid et al. 2008; Menkouchi et al. 2007; Hichour et al. 2000; Adikari et al. 1989; Amer et al. 2001), nanofiltration (Liu et al. 2007), membrane-based methods (Dieye et al. 1998; Mjengera and Mkongo 2003; Lhassani et al. 2001; Mameri et al. 2001), electrocoagulation ( $\mathrm{Hu}$ et al. 2003), and adsorption on to various adsorbents (Shihabudheen et al. 2006; Onyango et al. 2006; Tripathy et al. 2006; Mohapatra et al. 2004; Raichur and Jyoti Basu 2001). The choice of the method depends on conditions like area, concentration, availability of resources, etc. Among all these techniques, adsorption methods have more advantages because of their greater accessibility, economical, ease of operation, and effectiveness in removing fluoride from water to the maximum extent (Chauhan et al. 2007; Ayoob and Gupta 2008; Venkata Mohan et al. 2007).

Activated carbons prepared from various raw materials exhibit good fluoride uptake capacity (McKee and Jhonston 1934). Activated coconut shell carbon (Arulanantham et al. 1989), zirconium-impregnated ground nut shell carbon (Alagumuthu and Rajan 2010a), zirconium-impregnated coconut shell carbon (Sai sathish et al. 2007), Dolichos lablab carbon (Rao et al. 2009), zirconium-impregnated cashew nut shell carbon (Alagumuthu and Rajan 2010b), Phyllanthus emblica-activated carbon (Alagumuthu and Veeraputhiran 2011), Acacia farnesiana carbon (Kishore and Hanumantharao
2011), Moringa indica-activated carbon (Karthikeyan and Siva Elango 2007), Cynodon dactylon-activated carbon (Alagumuthu et al. 2011), Typha angustata-activated carbon (Hanumantharao et al. 2012a), Pine wood and Pine bark chars (Mohan et al. 2012), and activated carbon derived from steam pyrolysis of rice straw (Daifullah et al. 2007) have been explored for their adsorption nature towards fluoride. These techniques suffer from one or the other drawbacks, and a universally accepted, simple, eco-friendly and economical methods are still alluding researchers.

Hence, in this work, we searched for active carbons derived from plant materials belonging to different classes of plant kingdom. Our primary investigations indicated that there is strong affinity between fluoride and active carbons derived from barks of Vitex negundo plant. So, this work is devoted to study in depth the sorption characteristics of the said active carbon towards fluoride with respect to various physicochemical parameters such as adsorbent dosage, particle size, temperature, contact time, effect of $\mathrm{pH}$, presence of foreign ions, and initial fluoride concentration. Further, the mechanism of sorption is probed in order to establish theoretical grounds for the observed sorption phenomenon by making morphological studies adopting such techniques like Fourier transform infrared spectroscopy (FTIR), scanning electron microscopy (SEM), and energy-dispersive X-ray spectroscopy (EDX). Kinetics of the adsorption process has been also investigated. Further, the adoptability of the methodologies developed in this work has been tested with diverse groundwater samples collected from different places in Guntur District of Andhra Pradesh.

\section{Methods}

\section{Plant description}

Of the various classes of plant materials tested for their sorption abilities towards fluoride, it has been noted that the active carbon derived from the barks of $V$. negundo plant shows affinity for fluoride.

The $V$. negundo plant (Figure 1), known as five-leaved chaste tree, or Vavili or Nalla-vavili belongs to the Lamiaceae family in the plant kingdom. It is a small tree growing from 2 to $8 \mathrm{~m}$ in height with reddish-brown barks and is commonly found near bodies of water, grasslands, and mixed open forests. All parts of the plant like leaves, roots, bark, fruits, flowers, and seeds can be used medicinally in the form of powder, decoction, juice, oil, tincture, sugar/water/honey paste, dry extract.

\section{Preparation of active carbon}

The barks of $V$. negundo plant were collected in bulk, crushed into small pieces, washed with fluoride-free water, and completely dried under sunlight for 2 days. The dried material was carbonized in muffle furnace in the absence of air at $500^{\circ} \mathrm{C}$ for about $4 \mathrm{~h}$. After carbonization, the 


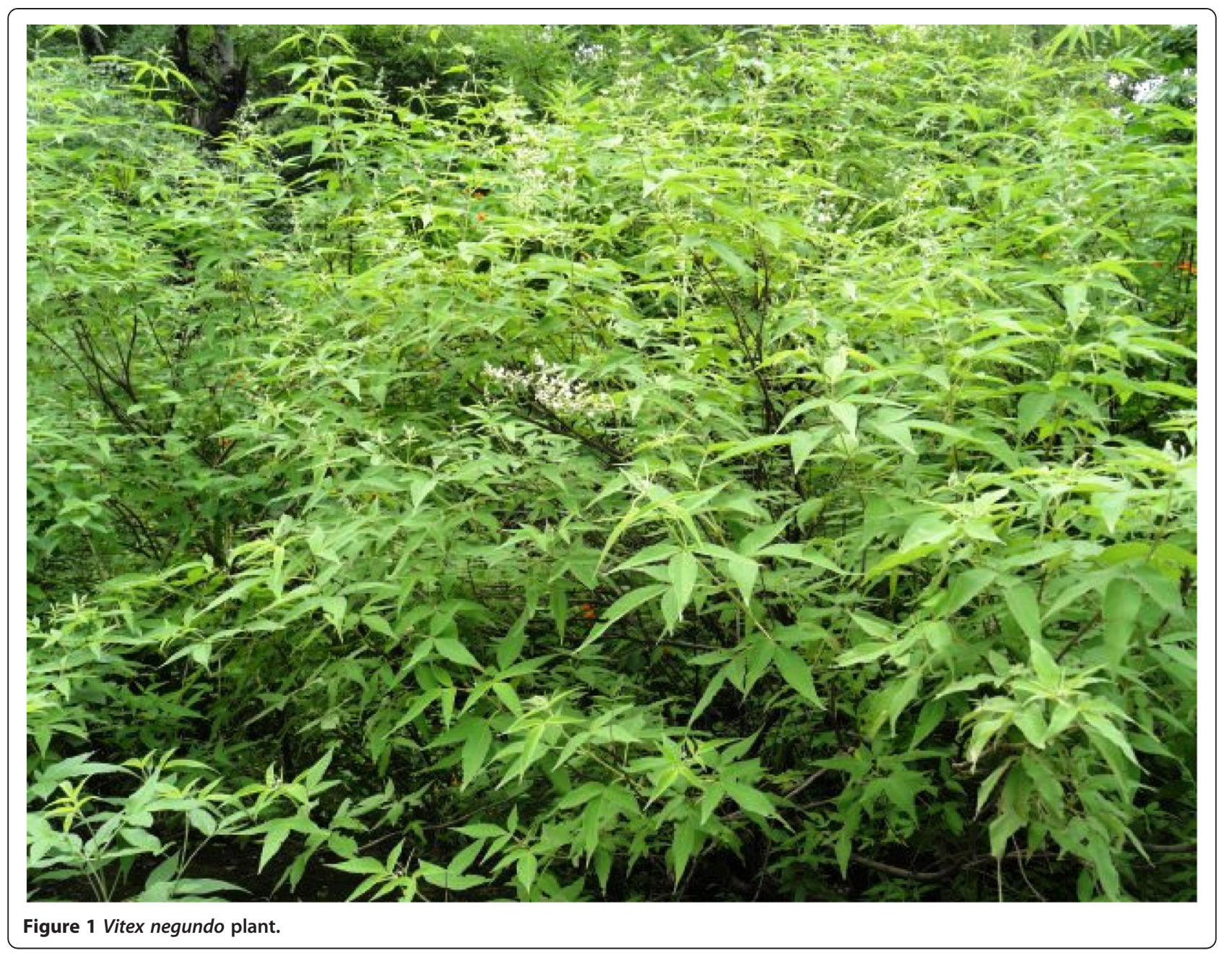

carbon was washed with fluoride-free water; the process was repeated for several times and then filtered. After that, the carbon was dried in air oven at $110^{\circ} \mathrm{C}$, and it was sieved into desired particle sizes and then the carbon was subjected to liquid phase oxidation by mixing with $0.1 \mathrm{~N}$ $\mathrm{HNO}_{3}$ and boiled for 2 to $3 \mathrm{~h}$ on flame. Then, the carbons were washed with double distilled water to remove the excess acid and dried at $150^{\circ} \mathrm{C}$ for $12 \mathrm{~h}$. This activated carbon prepared from $V$. negundo was named as NVNC.

\section{Reagents and chemicals}

All the chemicals used were of analytical reagent grade purchased from Merck. India Pvt. Ltd. (Bengaluru, India) and Sd. Fine Chemicals (Mumbai, Maharashtra, India), and all solutions were prepared by using double distilled water throughout this study. Stock solution of fluoride (100 ppm) was prepared and was suitably diluted as per the need. SPADNS solution, Zirconyl acid reagent, Acid ZirconylSPADNS reagent, and reference solution were prepared as per the literature.

\section{Experimental procedure}

Batch mode adsorption studies were adopted. Test solution of $5 \mathrm{mg} / \mathrm{l}$ of fluoride was prepared by diluting appropriate quantity of standard fluoride $(100 \mathrm{mg} / \mathrm{l})$ solution with double distilled water because the maximum concentration of fluoride reported in groundwater of most of the fluoride affected areas is around $5 \mathrm{mg} / \mathrm{l}$. From this $5 \mathrm{mg} / \mathrm{l}$ of fluoride simulated solution, $100 \mathrm{ml}$ of solution was pipetted out into a 250-ml conical flask at room temperature $30^{\circ} \mathrm{C} \pm 1^{\circ} \mathrm{C}$, and to it, weighed quantity of the prepared active carbon adsorbent was added. Then, the conical flask along with test solution and adsorbent was shaken in horizontal shaker at $120 \mathrm{rpm}$. At the end of the desired contact time, the conical flask was removed from shaker and allowed to stand for $2 \mathrm{~min}$ for settling the adsorbent, and the adsorbent was filtered using Whatman No.42 filter paper. The filtrate was analyzed for residual fluoride concentration by SPADNS method using UV-visible spectrophometer (Model No: Elico U.V-2600, ELICO, Hyderabad, India) as described in Standard Methods of Water and Waste Water Analysis (APHA (American Public Health Association) 1985) at $\lambda_{\max } 570 \mathrm{~nm}$. 


\section{Fluoride ion analysis}

The percentage removal of fluoride ion and amount adsorbed (in $\mathrm{mg} / \mathrm{g}$ ) were calculated using the following equations:

$$
\begin{aligned}
& \% \text { Removal }(\% R)=\frac{\left(C_{\mathrm{i}}-C_{\mathrm{e}}\right)}{C_{\mathrm{i}}} \times 100 \\
& \text { Amount adsorbed }\left(q_{\mathrm{e}}\right)=\frac{\left(C_{\mathrm{i}}-C_{\mathrm{e}}\right)}{m} V
\end{aligned}
$$

where $C_{\mathrm{i}}=$ initial concentration of the fluoride solution in $\mathrm{mg} / \mathrm{l}, C_{\mathrm{e}}=$ equilibrium concentration of the fluoride solution in $\mathrm{mg} / \mathrm{l}, m=$ mass of the adsorbent in grams, and $V=$ volume of the fluoride test solution in liters.

The same procedure has been adopted for the experiments carried out by varying the physicochemical parameters such as adsorbent dosage, $\mathrm{pH}$ of the fluoride solution, initial concentration of the standard fluoride solution, particle size, temperature, presence of foreign ions, and agitation time. Further, the same method was adopted in monitoring the concentration of fluoride in the characterization and adsorption studies.

\section{Methodologies adopted for the adsorbent characterization \\ Physicochemical parameters}

Various properties of the bio-sorbent, NVNC, were explored using standard methods, and the most important features of the results obtained were presented in Table 1. The $\mathrm{pH}$ for the activated carbon adsorbent was determined using the Elico $\mathrm{pH}$ meter, model LI-120, and the $\mathrm{pH}_{\mathrm{ZPC}}$ was determined using the $\mathrm{pH}$ equilibrium method (Kadirvelu et al. 2000; Marsh and Rodriguez-Reinoso 2006; Newcombe et al. 1993). Particle size was determined using American Standard Test Method (ASTM) sieves (El-Hendawy et al. 2001). Iodine number (ASTM D4607-94 2006; Hill and Marsh 1968), decolorizing power (Girgis and ElHendawy 2002; Rozada et al. 2005), and other parameters such as apparent density, moisture, loss on ignition, ash, water soluble matter, and acid soluble matter were analyzed by using standard test methods (Namasivayam and Kadirvelu 1997; BIS (Bureau of Indian Standards) 1989).

\section{Boehm titration}

The surface functional groups of oxygen were determined according to Boehm titration (Meldrum and Rochester 1990a; Boehm 1994; Bandosz et al. 1992). One gram of carbon sample was placed in $50 \mathrm{ml}$ of the solution containing $0.05 \mathrm{~N}$ of sodium hydroxide, $0.05 \mathrm{~N}$ of sodium carbonate, and $0.05 \mathrm{~N}$ of sodium bicarbonate. The bottles were sealed and shaken for $24 \mathrm{~h}$, and the mixture was filtered consequently. The excess base was titrated with $0.05 \mathrm{~N} \mathrm{HCl}$ solution. The number of acidic sites was determined under the assumptions that $\mathrm{NaOH}$

\begin{tabular}{|c|c|c|c|}
\hline Serial No. & \multicolumn{2}{|l|}{ Parameter } & Value \\
\hline 1 & \multicolumn{2}{|l|}{ Apparent density (g/ml) } & 0.288 \\
\hline 2 & \multicolumn{2}{|l|}{ Moisture content (\%) } & 6.98 \\
\hline 3 & \multicolumn{2}{|l|}{ Loss on Ignition (LOI) (\%) } & 90.26 \\
\hline 4 & \multicolumn{2}{|l|}{ Ash content (\%) } & 4.89 \\
\hline 5 & \multicolumn{2}{|l|}{ Water soluble matter (\%) } & 0.67 \\
\hline 6 & \multicolumn{2}{|l|}{ Acid soluble matter (\%) } & 0.81 \\
\hline 7 & \multicolumn{2}{|l|}{ Decolorizing power (mg/g) } & 373 \\
\hline 8 & \multicolumn{2}{|l|}{$\mathrm{pH}$} & 7.14 \\
\hline 9 & \multicolumn{2}{|l|}{$\mathrm{pH}_{\mathrm{ZPC}}$} & 9.35 \\
\hline 10 & \multicolumn{2}{|l|}{ lodine number (mg/g) } & 684 \\
\hline 11 & \multicolumn{2}{|l|}{ Particle size $(\mu)$} & 45 \\
\hline \multirow[t]{2}{*}{12} & \multirow[t]{2}{*}{ BET analysis - surface area $\left(\mathrm{m}^{2} / \mathrm{g}\right)$} & Before & 262.6 \\
\hline & & After & 194.8 \\
\hline 13 & \multicolumn{3}{|c|}{ Surface functional groups (meq/g) - Boehm titration } \\
\hline I & \multicolumn{2}{|l|}{ Carboxyl } & 1.247 \\
\hline ॥ & \multicolumn{2}{|l|}{ Lactonic } & 1.024 \\
\hline III & \multicolumn{2}{|l|}{ Phenolic } & 1.330 \\
\hline IV & \multicolumn{2}{|l|}{ Carbonyl } & 1.242 \\
\hline V & \multicolumn{2}{|l|}{ Total basic groups } & 6.876 \\
\hline
\end{tabular}

Table 1 Physicochemical properties of NVNC

neutralizes carboxylic, lactonic, and phenolic groups; that $\mathrm{Na}_{2} \mathrm{CO}_{3}$ neutralizes carboxylic and lactonic groups; and that $\mathrm{NaHCO}_{3}$ neutralizes only carboxylic groups. The number of basic sites was calculated from the amount of hydrochloric acid reacted with the carbon.

\section{BET surface area}

The Brunauer-Emmett-Teller (BET) surface area was determined using computer-controlled nitrogen gas adsorption analyzer at $77 \mathrm{~K}$ by Quantachrome NovaWin - Data Acquisition and Reduction for NOVA instruments version 10.01 (Quantachrome Instruments, Boynton Beach, FL, USA). The BET- $\mathrm{N}_{2}$ surface area was obtained by applying the BET equation to the adsorption data (Kadirvelu et al. 2000; Hashim 1994; Brunauer et al. 1938).

\section{FTIR analysis}

The surface functional groups on activated carbon adsorbent were examined using FTIR. The spectra were measured from 4,000 to $500 \mathrm{~cm}^{-1}$ on a BRUKER VERTEX 80/80v FTIR spectrometer (Bruker AXS, Inc., Madison, WI, USA), optical resolution of $<0.06 \mathrm{~cm}^{-1}$, with automatic and vacuum compatible beam splitter changer (BMS-c) option. Anhydrous $\mathrm{KBr}$ was used as a pellet material. 
SEM

The SEM is one of the most versatile instruments available for the examination and analysis of the microstructure morphology and chemical composition characterizations. The microphotographs of these carbons were recorded using LEO $1420 \mathrm{VP}$ compact variable pressure digital SEM, manufactured by Leo Electron Microscopy Ltd. (Cambridge, UK; beam voltage 500 to 2,000 V, magnifications $\times 250$ to $\times 65,000$, resolution $3 \mathrm{~nm}$ at $1,000 \mathrm{~V}$ ).

\section{EDS}

EDS, EDX, or XEDS is an analytical technique used for the elemental analysis to identify what those particular elements are and their relative proportions (atomic \%) of a sample. Each element has a unique atomic structure allowing unique set of peaks on its X-ray spectrum and was recorded using BRUKER EDX two-dimensional VANTEC-500 detector.

\section{Results and discussions}

The effect of various parameters such as adsorbent dosage, $\mathrm{pH}$, contact time, initial fluoride ion concentration, particle size, and presence of foreign ions on the adsorption of the fluoride ion from aqueous solution by activated carbon adsorbent, NVNC, have been represented by plots as shown in Figure 2.

\section{Effect of adsorbent dosage}

The percentage removal of the fluoride ion by adsorption onto activated carbon adsorbent was studied by

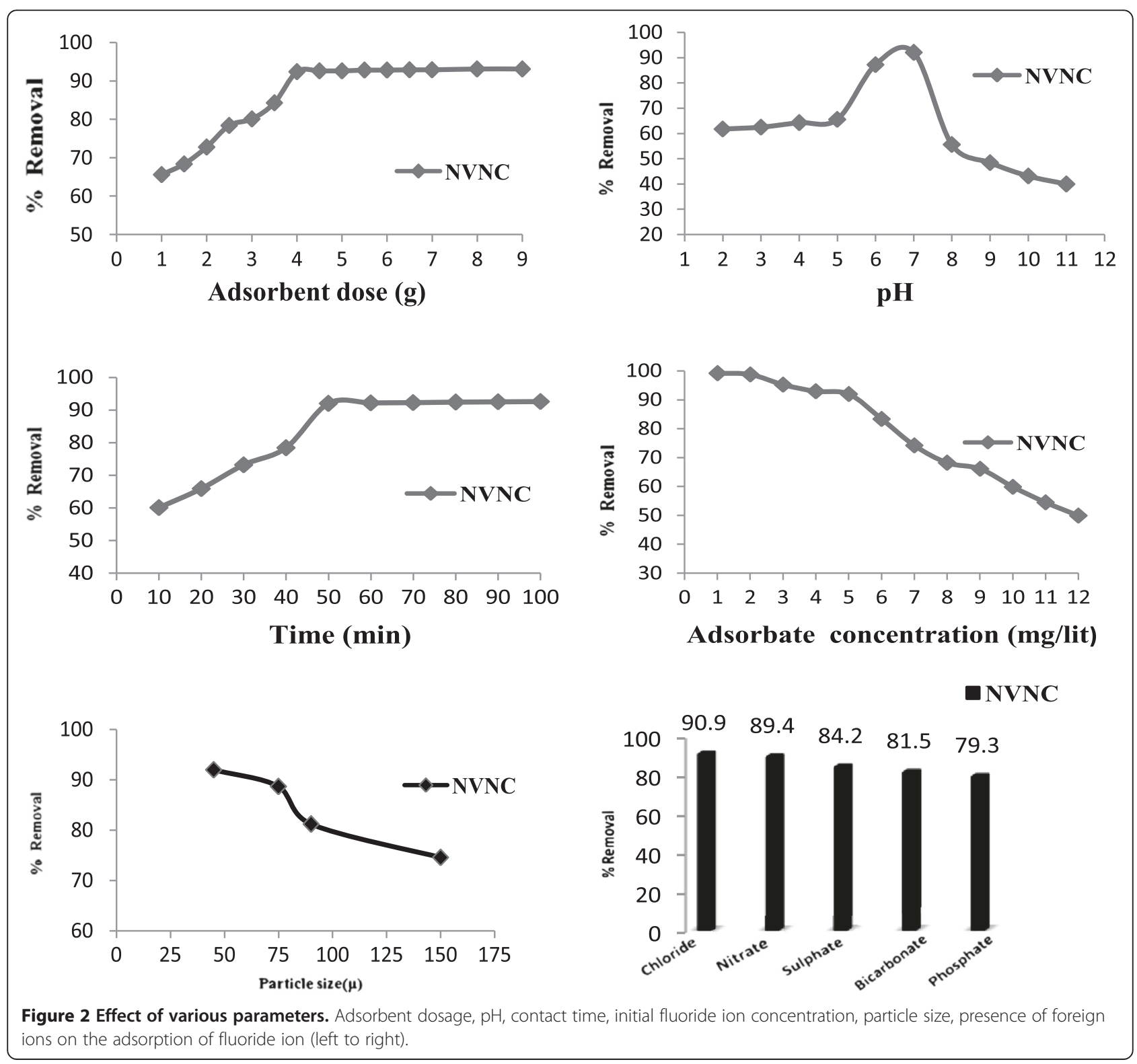


varying the dosage of the activated carbon adsorbent, $\mathrm{NVNC}$, in the range from 1.0 to $9.0 \mathrm{~g} / \mathrm{l}$, with a solution of $5 \mathrm{mg} / \mathrm{l}$ of fluoride ion concentration, at agitation time of $50 \mathrm{~min}$, at a fixed $\mathrm{pH}=7$ and at a temperature of $30^{\circ} \mathrm{C} \pm 1^{\circ} \mathrm{C}$. The results obtained were plotted as percentage removal of the fluoride ion versus adsorbent dosage as shown in Figure 2.

As can be inferred from the graphs that the percentage removal of the fluoride ion increases rapidly with increase in adsorbent dosage and after optimum dosage of $4.0 \mathrm{~g} / \mathrm{l}$, there has been no significant change in the percentage removal of the fluoride ion.

\section{Effect of $\mathrm{pH}$}

The effect of $\mathrm{pH}$ of the fluoride ion solution on the removal of the fluoride ion from aqueous solution was studied by varying the $\mathrm{pH}$ from 2 to 11 under optimum parameters, i.e., with a solution of $5 \mathrm{mg} / \mathrm{l}$ of fluoride ion concentration, contact times of $50 \mathrm{~min}$, dose of $4.0 \mathrm{~g} / \mathrm{l}$ for $\mathrm{NVNC}$, and at a temperature of $30^{\circ} \mathrm{C} \pm 1^{\circ} \mathrm{C}$. The results obtained were plotted as percentage removal of the fluoride ion versus $\mathrm{pH}$ as shown in Figure 2.

As $\mathrm{pH}$ is less than $\mathrm{pH}_{\mathrm{ZPC}}$ (Table 1), the net charge on surface of the solid activated carbon adsorbents is positive due to adsorption of excess $\mathrm{H}^{+}$, which favors adsorption due to columbic attraction. So, it is expected that acidic conditions favor the fluoride adsorption on to the surface of the solid activated carbon adsorbent. But according to fluoride speciation, neutral hydrofluoride which has less affinity towards active carbon adsorbents is predominant in the $\mathrm{pH}$ at less than 3 (Lagergren 1898), and so, less adsorption is observed at low $\mathrm{pH}$ conditions. At low $\mathrm{pH}$ values, the fluoride ion converts into neutral HF, and thereby anion exchanging nature is lost.

When $\mathrm{pH}$ increases from 2 to 11 , the percentage removal of the fluoride ion increases up to 7 , and then onwards, the percentage removal of the fluoride ion decreases. The optimum $\mathrm{pH}$ range has been found to be 6 to 7 and below, and above this range, the percentage removal of the fluoride ion is less (Figure 2).

\section{Effect of agitation time}

In adsorption system, contact time plays an important role, irrespective of the other experimental parameters affecting the adsorption kinetics. In order to study the effect of contact time on kinetics of adsorption of the fluoride ion, the adsorption experiments were conducted and the extent of removal of the fluoride ion was known by varying the contact time from 10 to $100 \mathrm{~min}$, with a solution of $5 \mathrm{mg} / \mathrm{l}$ of fluoride ion concentration, at a fixed $\mathrm{pH}=7$ and at a temperature of $30^{\circ} \mathrm{C} \pm 1^{\circ} \mathrm{C}$. The results obtained were plotted as percentage removal of the fluoride ion versus contact time (min) as shown in Figure 2.
As contact time increases, initially, the percentage removal of the fluoride ion is increased rapidly and after a certain time, approached an almost constant value indicating an attainment of equilibrium condition at which the rate of adsorption of fluoride onto the surface of the sorbent is equal to the rate of desorption. The rate of removal of the fluoride ion with time is higher at initial stages because of the availability of more active sites on the surface of the adsorbent, and with increase in contact time, the availability of active sites on the surface of the adsorbent decreases and this result in the decrease of the fluoride ion removal rate by the adsorbent. The decreased removal rate indicates the possible monolayer of the fluoride ions on the outer surface and pores of the adsorbent leading to pore diffusion onto inner surface of adsorbent particles (Namasivayam and Kadirvelu 1994; Yadav et al. 2006). From the observed results, the optimum contact time of activated carbon adsorbent NVNC is $50 \mathrm{~min}$.

\section{Effect of initial concentration}

The effect of initial concentration of the fluoride ion solution on the extent of removal of the fluoride ion from aqueous solution was studied by varying the initial concentration of the fluoride ion solution from 1 to $12 \mathrm{mg} / \mathrm{l}$ under constant parameters, i.e., at a fixed $\mathrm{pH}=7$, contact times of $50 \mathrm{~min}$ with a dose of $4.0 \mathrm{~g} / \mathrm{l}$, and at a temperature of $30^{\circ} \mathrm{C} \pm 1^{\circ} \mathrm{C}$. The results obtained were plotted as percentage removal of the fluoride ion versus initial concentration of the fluoride ion solution as shown in Figure 2.

With an increase in initial concentration of the fluoride ion solution, the percentage removal of the fluoride ion has been decreased due to insufficient number of active sites that are available on the activated carbon adsorbents to adsorb the fluoride ions from highly concentrated solution of the fluoride ions. At low concentrated solution of the fluoride ions, sufficient numbers of active sites are available on activated carbon adsorbents, and hence, most of the fluoride ions interact with the active sites on the activated carbon adsorbent, and thus, percentage removal of fluoride is more.

With an increase in the initial concentration of the fluoride ion solution from 1 to $12 \mathrm{mg} / \mathrm{l}$, the percentage removal $(\% R)$ of the fluoride ion is decreased from $99.2 \%$ to $49.9 \%$, and adsorption capacity $\left(q_{\mathrm{e}}\right)$ increased from 0.248 to $1.497 \mathrm{mg} / \mathrm{g}$ for NVNC.

\section{Effect of particle size}

The effect of particle size on fluoride removal by NVNC was explored to have a better understanding of the adsorption process with 45 to $150 \mu$ mesh sized particles under constant parameters, i.e., with a solution of $5 \mathrm{mg} / \mathrm{l}$ of fluoride ion concentration, at a fixed $\mathrm{pH}=7$, contact time of $50 \mathrm{~min}$ with a dose of $4.0 \mathrm{~g} / \mathrm{l}$, and at a temperature 
of $30^{\circ} \mathrm{C} \pm 1^{\circ} \mathrm{C}$. The results obtained were plotted as percentage removal of the fluoride ion vs. particle size as shown in Figure 2.

With an increase in particle size of activated carbon adsorbent, the percentage removal of the fluoride ion has been decreased due to insufficient number of surface active sites that are available on activated carbon adsorbent to adsorb fluoride ions. The rate of fluoride adsorption on smaller particles was significantly greater than that on larger sized particles. This is attributed to the fact that the lesser the particle size, the more will be the surface area and the more will be the number of active sites available for adsorption processes for a given amount of adsorbent. The percentage removal $(\% R)$ of the fluoride ion increases with decrease in particle size of activated carbon adsorbent, and hence, $45 \mu$ is fixed as the optimum size of the particles of activated carbon adsorbent.

\section{Interfering ions}

The effect of interfering ions on fluoride removal by NVNC was explored to have a better understanding of the adsorption process with $50 \mathrm{mg} / \mathrm{l}$ concentration of interfering ions such as chloride, nitrate, sulfate, bicarbonate, and phosphate under constant parameters, i.e., with a solution of $5 \mathrm{mg} / \mathrm{l}$ of fluoride ion concentration, at a fixed $\mathrm{pH}=7$, contact time of $50 \mathrm{~min}$ with a dose of $4.0 \mathrm{~g} / \mathrm{l}$, and at a temperature of $30^{\circ} \mathrm{C} \pm 1^{\circ} \mathrm{C}$. The results obtained were presented in Table 2 and plotted as shown in Figure 2.

The impact of interfering ions present in water on fluoride adsorption by the activated carbon adsorbent, NVNC, follows the order $\mathrm{PO}_{4}^{3-}>\mathrm{HCO}_{3}^{-}>\mathrm{SO}_{4}^{2-}>\mathrm{NO}_{3}^{-}>\mathrm{Cl}^{-}$.

Previous research indicates that chloride and nitrate ions form outer sphere surface complexes while sulfate ions form both outer sphere and inner sphere surface complexes (Onyango et al. 2004). Hence, chloride ions as well as nitrate ions have less interference with fluoride removal while sulfate ions have some significant effect on fluoride removal efficiency. The most important factor affecting fluoride removal efficiency was the bicarbonate alkalinity of the water, and it reduces the positive charge on the active sites of the active carbon and thereby reduces the affinity of the active sites of the adsorbent for fluoride adsorption. This results in the decrease in the percentage removal of the fluoride ion from water.

Phosphate ion which is having high negative charge compared to other anions needs three close surface groups and adsorbed on adsorbents as inner sphere surface complex. This inner spherically adsorbing phosphate ion (Goldberg and Sposito 1984a, 1984b; Zhang and Spark 1990) can significantly interfere with the fluoride ion and hence decrease in the percentage removal of the fluoride ion from water. In the presence of interfering ions chloride, nitrate, sulfate, bicarbonate, and phosphate, the percentage removal of the fluoride ion decreases from $92 \%$ to $90.9 \%, 89.4 \%, 84.2 \%, 81.5 \%$, and $79.3 \%$, respectively.

\section{Effect of temperature}

The effect of solution temperature was studied by conducting the experiment at different temperatures 303, 313 , and $323 \mathrm{~K}$ and at optimum conditions, i.e., with a solution of $5 \mathrm{mg} / \mathrm{l}$ of fluoride ion concentration, at a fixed $\mathrm{pH}=7$, contact time of $50 \mathrm{~min}$, dosage of $4.0 \mathrm{~g} / \mathrm{l}$ for NVNC, and results obtained were plotted as $\ln K_{\mathrm{d}}$ vs. $1 / T$ as shown in Figure 3. Thermodynamic parameters of the adsorption process such as change in free energy $(\Delta G)(\mathrm{kJ} / \mathrm{mole})$, change in enthalpy $(\Delta H)(\mathrm{kJ} / \mathrm{mole})$, and change in entropy $(\Delta S)(\mathrm{kJ} / \mathrm{mole})$ were determined at different temperatures by using the equations (Alagumuthu and Rajan 2010a; Karthikeyan and Siva Elango 2007)

$$
\begin{aligned}
& \Delta G=-R T \ln K_{\mathrm{d}} \\
& \ln K_{\mathrm{d}}=\Delta S / R-\Delta H / R T \\
& K_{\mathrm{d}}=q_{\mathrm{e}} / C_{\mathrm{e}} \text { and } \\
& \Delta G=\Delta H-T \Delta S
\end{aligned}
$$

where $K_{\mathrm{d}}$ is the distribution coefficient for the adsorption, $q_{\mathrm{e}}$ is the amount of fluoride ion adsorbed on the activated carbon adsorbent per liter of solution at equilibrium, $C_{\mathrm{e}}$ is the equilibrium concentration of fluoride ion solution, $T$ is the absolute temperature in Kelvin, $R$ is the gas constant. $\Delta G$ is the change in free energy, $\Delta H$ is the change in enthalpy, and $\Delta S$ is the change in entropy.

The values of $\Delta H$ and $\Delta S$ were obtained from the slope and intercept of a plot between $\ln K_{\mathrm{d}}$ and $1 / T$ and $\Delta G$ values were obtained from the equation

\begin{tabular}{|c|c|c|c|c|c|c|c|}
\hline \multirow[t]{2}{*}{ Serial No. } & \multirow[t]{2}{*}{ Adsorbent } & \multirow[t]{2}{*}{$\begin{array}{l}\text { Maximum extractability at } \\
\text { optimum conditions }\end{array}$} & \multicolumn{5}{|c|}{$\begin{array}{l}\text { Extractability of fluoride ion in the presence of } 50 \mathrm{mg} / \mathrm{l} \text { of interfering ions } \\
\text { at optimum (pHs) }\end{array}$} \\
\hline & & & $\mathrm{Cl}^{-}$ & $\mathrm{NO}_{3}^{-}$ & $\mathrm{S} \mathrm{O}_{4}^{2-}$ & $\mathrm{HCO}_{3}^{-}$ & $\mathrm{PO}_{4}^{3-}$ \\
\hline 1 & NVNC & $92.0 \%, \mathrm{pH}: 7,50 \mathrm{~min}$ & $\begin{array}{l}90.9 \%, \mathrm{pH}: 7 \\
50 \mathrm{~min}\end{array}$ & $\begin{array}{l}89.4 \%, \mathrm{pH}: 7 \\
50 \min \end{array}$ & $\begin{array}{l}84.2 \%, \mathrm{pH}: 7 \\
50 \mathrm{~min}\end{array}$ & $\begin{array}{l}81.5 \% \mathrm{pH}: 7 \\
50 \mathrm{~min}\end{array}$ & $\begin{array}{l}79.3 \%, \mathrm{pH}: 7, \\
50 \mathrm{~min}\end{array}$ \\
\hline
\end{tabular}
$\Delta G=\Delta H-T \Delta S$ and tabulated (Horsfall and Spiff 2005; Viswanathan and Meenakshi 2010).

Table 2 Effect of interfering ions on fluoride ion removal from aqueous solution by the activated carbon: NVNC 


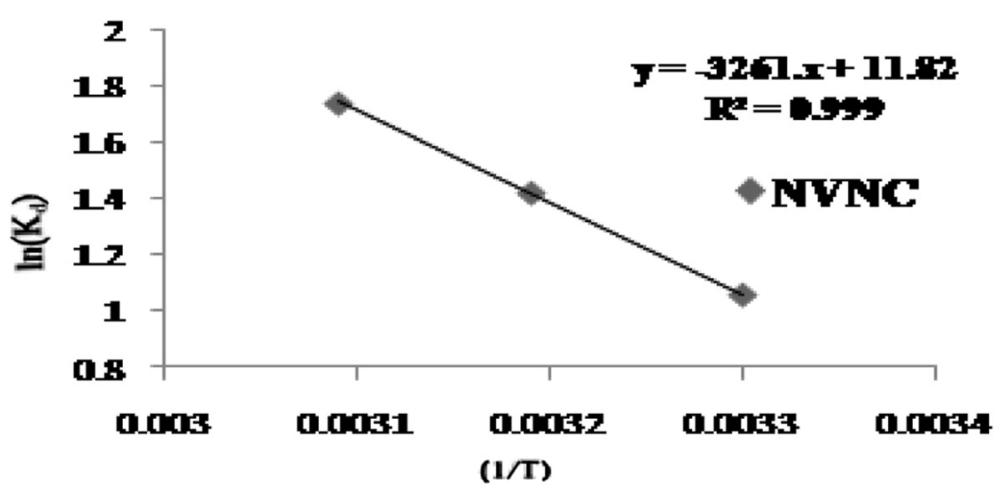

Figure 3 Effect of temperature on the adsorption of fluoride ion.

It is observed that with an increase in the temperature from 303 to $323 \mathrm{~K}\left(30^{\circ} \mathrm{C}\right.$ to $\left.50^{\circ} \mathrm{C}\right)$, the percentage removal of fluoride ion increases from $92 \%$ to $95.8 \%$ for NVNC.

As the temperature increases, the thickness of the outer surface of the activated carbon adsorbent decreases and the kinetic energy of the fluoride ion increases, and hence, the rate of diffusion of the fluoride ion increases across the external boundary layer and internal pores of the activated carbon adsorbent.

As can be inferred from the Table 3, the values of $\Delta H$ are positive, which indicates the physisorption and endothermic nature of adsorption (Bouberka et al. 2005). The $R^{2}$ values close to one also indicates that adsorption process is endothermic nature. The positive values of $\Delta S$ indicate the increased disorder and randomness at the solid solution interface of the fluoride ion with the adsorbent (Sairam Sundaram et al. 2009). The negative values of $\Delta G$ indicate the spontaneous nature of adsorption process.

\section{Adsorption isotherms}

The adsorption isotherms are one of the most significant methods for representing the adsorption capacity of the adsorbent and the mechanism of the adsorption system. The purpose of an adsorption isotherm is to evaluate the relation between the fluoride concentrations remaining in the bulk solution to the amount of fluoride adsorbed at the solid/solution interface. Four well-known models, Freundlich, Langmuir, Dubinin-Radushkevich, and Temkin adsorption isotherms have been selected for describing adsorption isotherms at a constant temperature for water and wastewater treatment application.
Linear form of Freundlich isotherm equation is as follows:

$$
\log \left(q_{\mathrm{e}}\right)=\log k_{\mathrm{f}}+\left(\frac{1}{n}\right) \log C_{\mathrm{e}}
$$

Linear form of Langmuir isotherm equation is as follows:

$$
\left(C_{\mathrm{e}} / q_{\mathrm{e}}\right)=\left(a_{\mathrm{L}} / k_{\mathrm{L}}\right) C_{\mathrm{e}}+\mathbf{1} / k_{\mathrm{L}}
$$

The significant features of the Langmuir isotherm model can be defined by the dimensionless constant separation factor $R_{\mathrm{L}}$ which is expressed by the following equation:

$$
R_{\mathrm{L}}=\mathbf{1} /\left(\mathbf{1}+a_{\mathrm{L}} C_{\mathrm{i}}\right)
$$

where, $k_{\mathrm{F}}$ and $1 / n$ are the Freundlich constants, $C_{\mathrm{i}}$ is the initial fluoride ion concentration, $q_{\mathrm{e}}(\mathrm{mg} / \mathrm{g})$ is the amount of fluoride ions adsorbed per unit weight of the adsorbent $(\mathrm{mg} / \mathrm{g})$, and $k_{\mathrm{L}}$ and $a_{\mathrm{L}}$ are the Langmuir constants related to capacity and energy of adsorption, respectively.

In defluoridation of water using activated carbon adsorbents, linear plot of $\log \left(q_{\mathrm{e}}\right)$ vs. $\log \left(C_{\mathrm{e}}\right)$ at different fluoride ion concentrations were found to be linear as shown in Figure 4 and confirmed the applicability of Freundlich isotherm model. When $C_{\mathrm{e}} / q_{\mathrm{e}}$ is plotted against $C_{\mathrm{e}}$, a straight line was observed as shown in Figure 4 . The slope, $a_{\mathrm{L}} / k_{\mathrm{L}}$, and intercept, $1 / k_{\mathrm{L}}$, of the straight line showed that the adsorption followed the Langmuir isotherm.

The Freundlich constants $k_{\mathrm{F}}$ and $1 / n$ were calculated from the intercept and slope of the plots, respectively. The Langmuir constants $a_{\mathrm{L}}$ and $k_{\mathrm{L}}$ were calculated from the slope and intercept of the straight line, respectively. The observed linear relationships were statistically

Table 3 Thermodynamic parameters of fluoride ion adsorption on NVNC

\begin{tabular}{llllll}
\hline Parameter & $\mathbf{\Delta} \mathbf{H}(\mathbf{k J} / \mathbf{m o l})$ & $\boldsymbol{\Delta S}(\mathbf{J} / \mathbf{m o l} / \mathbf{K})$ & & $\boldsymbol{\Delta} \mathbf{G}(\mathbf{k J} / \mathbf{m o l})$ & \\
\hline Temperature $(\mathrm{K})$ & & & 303 & 313 & $\boldsymbol{R}^{\mathbf{2}}$ \\
NVNC & 27.11 & 98.27 & -2.6658 & -3.6485 & -4.999 \\
\hline
\end{tabular}




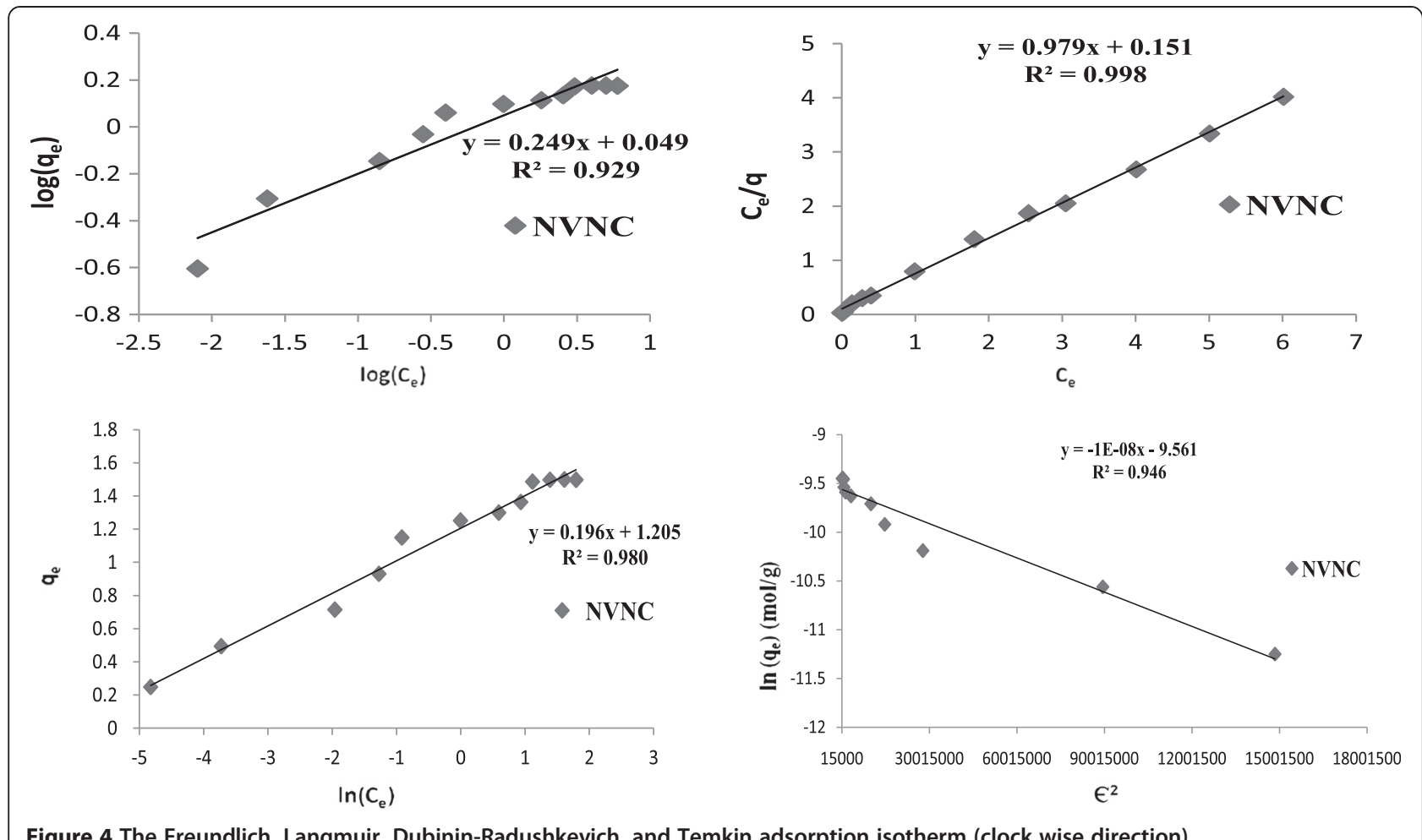

Figure 4 The Freundlich, Langmuir, Dubinin-Radushkevich, and Temkin adsorption isotherm (clock wise direction).

important as evidenced from the correlation coefficients ( $R^{2}$ values) close to unity, which indicated that the applicability of these two adsorption isotherms confirmed the heterogeneous surface of the adsorbent and the monolayer coverage of the fluoride ion on the active carbon surface.

According to Hall et al. (1966), the separation factor $R_{\mathrm{L}}$ indicates the isotherm's shape and the nature of the adsorption process as unfavorable $\left(R_{\mathrm{L}}>1\right)$, linear $\left(R_{\mathrm{L}}=1\right)$, favorable $\left(0<R_{\mathrm{L}}<1\right)$, and irreversible $\left(R_{\mathrm{L}}=0\right)$. The correlation coefficient $\left(R^{2}\right)$ value was higher for the activated carbon adsorbent NVNC in the Langmuir isotherm than in the Freundlich isotherm, and the value of dimensionless separation factor $\left(R_{\mathrm{L}}\right), 0.0299$, which was found to be fraction in the range of 0 to 1 indicates the favorability of the Langmuir isotherm than the Freundlich isotherm.

Linear form of Temkin isotherm equation is as follows:

$q_{\mathrm{e}}=B \ln C_{\mathrm{e}}+B \ln A$ where $R T / b=B$

Linear form of Dubinin-Radushkevich isotherm equation is as follows:

$\ln q_{\mathrm{e}}=-B \varepsilon^{2}+\ln Q_{\mathrm{m}}$ where $\varepsilon=R T \ln \left(1+1 / C_{\mathrm{e}}\right)$ where $B$ is the Temkin constant related to heat of sorption ( $/ \mathrm{mol}), A$ is the Temkin isotherm constant $(\mathrm{L} / \mathrm{g}), b$ is the Temkin isotherm constant, $q_{\mathrm{m}}(\mathrm{mol} / \mathrm{g})$ is the DubininRadushkevich monolayer adsorption capacity, $\beta$ is a constant related to energy, $E=1 \sqrt{ } 2 \beta, \varepsilon$ is the polanyi potential, $R$ is a gas constant $(8.314 \mathrm{~J} / \mathrm{mol} \mathrm{K}), T$ is the absolute temperature, $C_{\mathrm{e}}$ is the equilibrium concentration of the fluoride solution in $\mathrm{mg} / \mathrm{l}$, and $q_{\mathrm{e}}$ is the amount of fluoride ions adsorbed per unit weight of the adsorbent $(\mathrm{mg} / \mathrm{g})$.

In defluoridation of water using activated carbon adsorbents, linear plot of $\left(q_{\mathrm{e}}\right)$ vs. $\ln \left(C_{\mathrm{e}}\right)$ at different fluoride ion concentrations were found to be linear as shown in Figure 4 and confirmed the applicability of Temkin $\left(R^{2}=0.980\right)$ isotherm model. When $\ln \left(q_{\mathrm{e}}\right)(\mathrm{mol} / \mathrm{g})$ is plotted against $\varepsilon^{2}$, a straight line with slope $\beta$ and intercepts $\ln q_{\mathrm{m}}$ showed that the adsorption followed the Dubinin-Radushkevich $\left(R^{2}=0.946\right)$ isotherm as shown in Figure 4.

The Temkin constants $A$ and $B$ were calculated from the intercept and slope of the plots. The DubininRadushkevich constant, $\beta$, can be calculated from the slope of the straight line. The observed linear relationships were statistically important as evidenced from the correlation coefficients ( $R^{2}$ values) close to unity, which indicated the applicability of these two adsorption isotherms and confirmed the heterogeneous surface of the adsorbent. And the Dubinin-Radushkevich mean free energy, $E$, can be calculated from the relation $E=1 \sqrt{ } 2 \beta$. The mean free energy, $E$, was found to be $7.07 \mathrm{~kJ} / \mathrm{mol}$ for the activated carbon adsorbent NVNC. This indicates that the mechanism of adsorption is 'physisorption'. When the $E<8 \mathrm{~kJ} / \mathrm{mol}$, it is an indication of physisorption (Monika et al. 2009) (nonspecific adsorption) dominating the chemisorptions and ion exchange. 
Physisorption is also called nonspecific adsorption which occurs as a result of long-range weak van der Waals forces between adsorbates and adsorbents. According to Atkins (Atkins 1999) also, if the free energy, $E$ and Temkin heat of sorption $(B)$ are less than $20 \mathrm{~kJ} / \mathrm{mol}$, the physisorption is predominant.

The values of the Freundlich and Langmuir Temkin and Dubinin-Radushkevich adsorption isotherm constants together with the correlation coefficients values were presented in Table 4.

\section{Kinetic study of adsorption}

In the present work, some kinetic models, namely, pseudo-first-order model, pseudo-second-order model, Weber and Morris intraparticle diffusion model, Bangham's pore diffusion model, and Elovich equations are discussed to study the rate and kinetics of adsorption of the fluoride ion onto the activated carbon adsorbent NVNC. The kinetics of adsorption describes the solute uptake rate, which in turn governs the residence time of adsorption reaction.

\section{The pseudo-first-order model}

On adsorption of the fluoride ion onto the activated carbon adsorbent, linear plot of $\log \left(q_{\mathrm{e}}-q_{\mathrm{t}}\right)$ vs. $t$ at different contact times for the extent of removal of the fluoride ion from water is applied to confirm the applicability of pseudo-first-order model. The pseudo-firstorder equation is $\log \left(q_{\mathrm{e}}-q_{\mathrm{t}}\right)=\log q_{\mathrm{e}}-k_{1} t / 2.303$

It was found that the plot of $\log \left(q_{\mathrm{e}}-q_{\mathrm{t}}\right)$ vs. $t$ should give a linear relationship from which values of the $k_{1}$ and $q_{\mathrm{e}}$ could be determined from the slope and intercept of the plot, respectively.

\section{The pseudo-second-order model}

On adsorption of fluoride ion on to the activated carbon adsorbent, linear plot of $\left(t / q_{\mathrm{t}}\right)$ vs. $t$ at different contact times for the extent of removal of the fluoride ion from water is applied to confirm the applicability of pseudo- second-order model. The pseudo-first-order equation is $t / q_{\mathrm{t}}=1 / k_{2} q_{\mathrm{e}}^{2}-\left(1 / q_{\mathrm{e}}\right) t$.

The plot of $\left(t / q_{\mathrm{t}}\right)$ vs. $t$ should give a linear relationship from which the values of the $k_{2}$ and $q_{\mathrm{e}}$ could be determined from the intercept and slope of the plot, respectively.

\section{Weber and Morris intraparticle diffusion model}

On adsorption of the fluoride ion onto the activated carbon adsorbent, linear plot of $\left(q_{\mathrm{t}}\right)$ vs. $t^{1 / 2}$ at different contact times for the extent of removal of fluoride ion from water is applied to confirm the applicability of Weber and Morris intraparticle diffusion model. The Weber and Morris intraparticle diffusion equation is as follows:

$$
q_{\mathrm{t}}=k_{\mathrm{ip}} t^{1 / 2}+c
$$

The plot of $\left(q_{\mathrm{t}}\right)$ vs. $t^{1 / 2}$ should give a linear relationship from which the value of the Weber and Morris intraparticle diffusion rate constant, $k_{\mathrm{ip}}$, could be determined from the slope of the plot.

\section{Bangham's pore diffusion model}

On adsorption of the fluoride ion onto the activated carbon adsorbent, linear plot of $\log \left[\log \left(C_{\mathrm{i}} /\left(C_{\mathrm{i}}-q_{\mathrm{t}} m\right)\right)\right]$ vs. $\log (t)$ at different contact times for the extent of removal of the fluoride ion from water is applied to confirm the applicability of Bangham's pore diffusion model. Bangham's pore diffusion equation is as follows:

$$
\log \left[\log \left(C_{\mathrm{i}} / C_{\mathrm{i}}-q_{\mathrm{t}} m\right)\right]=\log \left(k_{\mathrm{o}} / 2.303 V\right)+\alpha \log (t)
$$

The linear plots of $\log \left[\log \left(C_{\mathrm{i}} /\left(C_{\mathrm{i}}-\mathrm{q}_{\mathrm{t}} \mathrm{m}\right)\right)\right]$ vs. $\log (t)$ should give a linear relationship from which the value of the Bangham's pore diffusion rate constant, $k_{\mathrm{o}}$, and a constant, $\alpha$, could be determined from the intercept and slope of the plot, respectively.

\section{Elovich equation}

On adsorption of the fluoride ion onto the activated carbon adsorbent, linear plot of $\left(q_{\mathrm{t}}\right)$ vs. $\ln (t)$ at different

\begin{tabular}{|c|c|c|c|c|c|}
\hline Serial No. & Adsorption isotherms and kinetic models & & Slope & Intercept & $R^{2}$ \\
\hline 1 & Freundlich isotherm & & 0.249 & 0.490 & 0.929 \\
\hline 2 & Langmuir isotherm & $R_{\mathrm{L}}=0.0299$ & 0.979 & 0.151 & 0.998 \\
\hline 3 & Temkin isotherm & $B=0.196 \mathrm{~J} / \mathrm{mol}$ & 0.196 & 1.205 & 0.980 \\
\hline 4 & Dubinin-Radushkevich isotherm & $E=7.07 \mathrm{~kJ} / \mathrm{mol}$ & $-1 E-08$ & -9.561 & 0.946 \\
\hline 5 & Pseudo-first-order model & & -0.012 & -0.258 & 0.989 \\
\hline 6 & Pseudo-second-order model & & 0.777 & 7.320 & 0.994 \\
\hline 7 & Bangham's pore diffusion model & & 0.538 & -0.976 & 0.902 \\
\hline 8 & Elovich model & & 0.207 & 0.249 & 0.912 \\
\hline 9 & Weber and Morris intraparticle diffusion model & & 0.066 & 0.567 & 0.874 \\
\hline
\end{tabular}

Table 4 Adsorption and kinetic parameters 
contact times for the extent of removal of the fluoride ion from water is applied to confirm the applicability of Elovich equation. The Elovich equation is as follows:

$$
q_{\mathrm{t}}=1 / \beta \ln (\alpha \beta)+1 / \beta \ln (t)
$$

The linear plot of $\left(q_{\mathrm{t}}\right)$ vs. $\ln (t)$ should give a linear relationship from which the value of the constants $\alpha$ and $\beta$ could be determined from the intercept and slope of the plot, respectively.

The plots of all these five kinetic models are as shown in Figure 5.

The values of pseudo-first-order, pseudo-second-order, Weber and Morris intraparticle diffusion, Bangham's pore diffusion, and Elovich model constants together with the correlation coefficients values were presented in Table 4 .
The experimental data revealed that of the five kinetic models, namely, pseudo-first-order, pseudo-secondorder, Weber and Morris intraparticle diffusion, Bangham's pore diffusion, and Elovich models when correlated with the linear forms, the correlation coefficient value of $R^{2}=0.994$ for the pseudo-second-order model is greater than the other kinetic models, and this indicates that the pseudo-second-order model is the best fit to the experimental data of the present studied adsorption system. The next to follow the order is the pseudo-firstorder model with $R^{2}=0.989$, Elovich model with $R^{2}=0.912$, Bangham's pore diffusion model with $R^{2}=0.902$, and the least is Weber and Morris intraparticle diffusion model $\left(R^{2}=0.874\right)$.

The correlation coefficient of $R^{2}=0.912$ value for the Elovich equation suggest that the diffusion of the

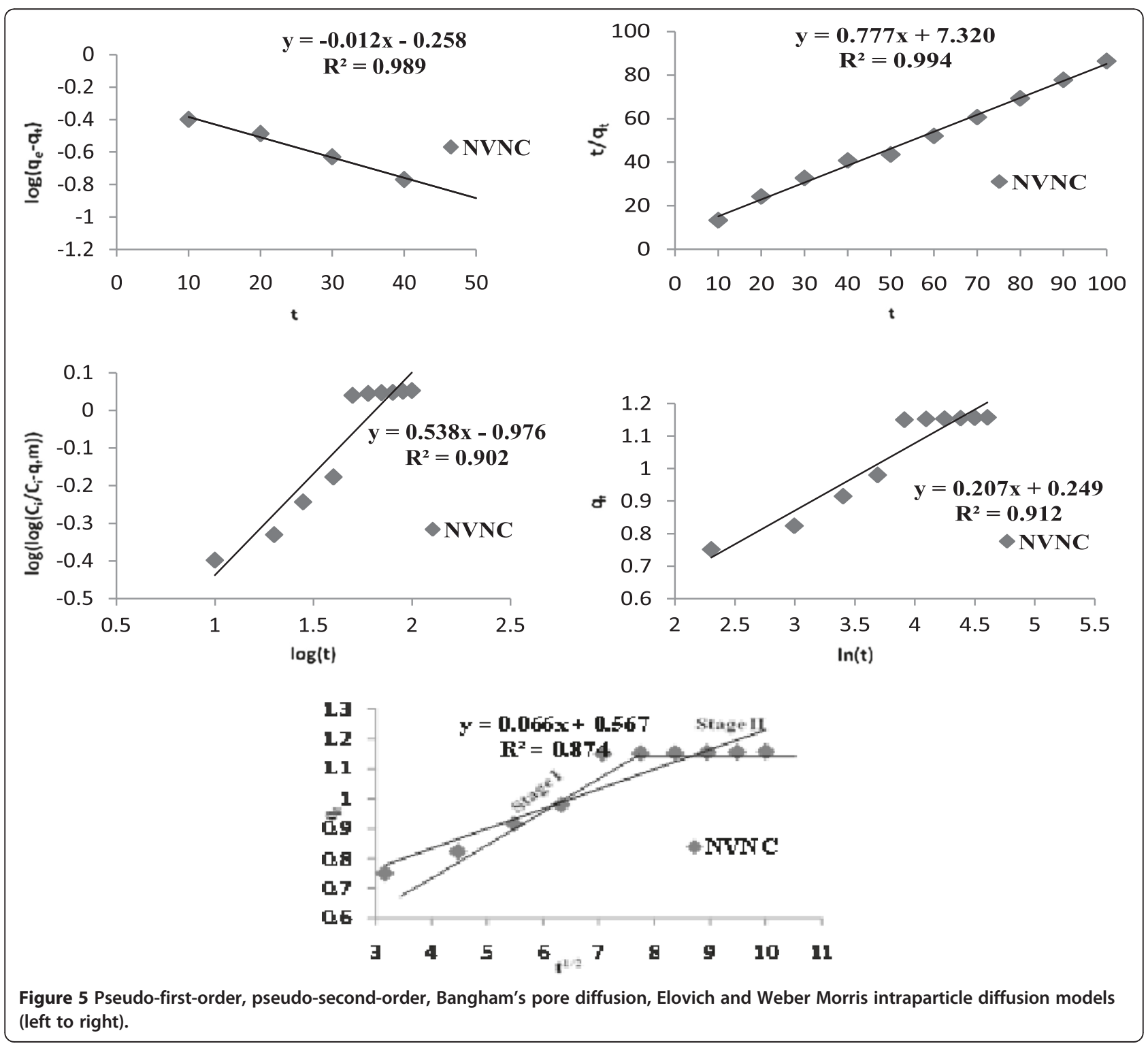


fluoride ion follows the Elovich kinetics pattern and the rate determining step is diffusion in nature, and this diffusional rate limiting is more prominent in fluoride ion adsorption onto the activated carbon adsorbent. The correlation coefficient of $R^{2}=0.902$ value indicates that the adsorption kinetics follows the Bangham's equation and the adsorption of fluoride ion onto the activated carbon adsorbent is Bangham's pore diffusion controlled.

The low correlation coefficient value of $R^{2}=0.874$ for the Weber and Morris intraparticle diffusion model indicates that the intraparticle diffusion model does not apply to the present studied adsorption system.

\section{Characterization of the adsorbent NVNC}

The different physicochemical properties of the active carbon, NVNC, were presented in Table 1 . The surface characteristics make it fit for adsorption of the fluoride ion. Zero point charge $\left(\mathrm{pH}_{\mathrm{ZPC}}\right)$ of the adsorbent is more important for adsorption processes. In the present study, adsorption of anion is favored because for the NVNC, the obtained result is $\mathrm{pH}<\mathrm{pH}$ ZPC. The BET surface area before defluoridation was $262.6 \mathrm{~m}^{2} / \mathrm{g}$, and the value reduces to $194.8 \mathrm{~m}^{2} / \mathrm{g}$ after defluoridation. The presence of surface functional groups of oxygen like phenol, carbonyl, hydroxyl, and lactones were determined according to Boehm titration, and from Table 1, it was clear that for activated carbon, the total basic groups were greater than the total acidic groups. The presence of these groups was confirmed by FTIR results.

\section{FTIR spectroscopy of NVNC before and after defluoridation}

It gives confirmation for the presence of specific functional groups on the surface of carbon materials. Several characteristic bands were observed in the FTIR spectrum of NVNC (vide Table 5 and Figure 6), and each of the bands can be assigned to specific functional group based on the previous assignments made in literature.
Even though a cluster of functional groups were present on the carbon surface, the prominent among them was a sharp and intense band centered around $1,691.51 \mathrm{~cm}^{-1}$ which was attributed to the carbonyl $(-\mathrm{C}=\mathrm{O})$ stretching vibration of quinine or quinone or conjugated ketone (Ji et al. 2007; Biniak et al. 1997; Yu et al. 2008; Ishizaki and Marti 1981; Shin et al. 1997; Moreno-Castilla et al. 1998; Starsinic et al. 1983; Zawadzki 1989). The carbon surface is oxidized by treatment with concentrated $\mathrm{HNO}_{3}$ leading to the generation of such quinone type carbon functional groups which bear significance in the redox chemistry of carbon materials. Carbonyl functional groups are known to be pronounced in oxidized carbon materials rather than the original parent carbon material (Budinova et al. 2006). In addition, stretching vibration bands of surface and hydrogen bonded -O-H group of alcohols, phenols, and chemisorbed water (Daifullah et al. 2003; Ibrahim et al. 1980; Yang and Lua 2003; Puziy et al. 2003), the peaks pertaining to asymmetric $-\mathrm{C}-\mathrm{H}$ stretching vibration of aliphatic $-\mathrm{CH}_{3}$ or $-\mathrm{CH}_{2}$ groups (Biniak et al. 1997; Yu et al. 2008; Puziy et al. 2003; Rajeshwari et al. 2001); peaks due to the in plane bending vibration of $-\mathrm{C}-\mathrm{H}$ of methylene group (Budinova et al. 2006; Rajeshwari et al. 2001; Ozgul et al. 2007); peaks due to -C-O stretching in alcohols, phenols, ethers, esters, acids, epoxides, lactones, and carboxylic anhydrides (Shin et al. 1997; Budinova et al. 2006; Rajeshwari et al. 2001; Gomez-Serrano et al. 1994; Figueiredo et al. 1999; El-Hendawy 2003; Park et al. 1997; Attia et al. 2006; Lapuente et al. 1998); the peaks pertaining to the $-\mathrm{C}=\mathrm{O}$ stretching in carbonyl and carboxyl groups and in lactones (Zawadzki 1989; Nageswara Rao et al. 2011; Fanning and Vannice 1993; Painter et al. 1985; Zhuang et al. 1994); peaks due to the out-of-plane deformation vibrations of $-\mathrm{C}-\mathrm{H}$ group in aromatic structures (Nageswara Rao et al. 2011; Meldrum and

Table 5 Bands assigned to the surface functional groups of NVNC before and after

\begin{tabular}{|c|c|c|c|}
\hline \multirow[b]{2}{*}{$\begin{array}{l}\text { Serial } \\
\text { No. }\end{array}$} & \multicolumn{3}{|l|}{ Wave number $\left(\mathrm{cm}^{-1}\right)$} \\
\hline & NVNC (before) & NVNC (after) & Bond stretching \\
\hline 1 & $\begin{array}{l}3855.00,3743.37,3676.37,3617.38 \\
3563.84,3386.65,3289.23\end{array}$ & $\begin{array}{l}3843.03,3745.86,3679.14,3614.13 \\
3562.86,3334.89,3227.25\end{array}$ & $-\mathrm{O}-\mathrm{H}$ in alcohols, acids, phenols, and $-\mathrm{N}-\mathrm{H}$ in amines and amides \\
\hline 2 & $2932.15,2876.53,2822.24,2786.84$ & $2957.30,2866.67,2828.66,2747.80$ & $-\mathrm{C}-\mathrm{H}$ in $-\mathrm{CH}_{3}$ and $-\mathrm{CH}_{2}$ \\
\hline 3 & $1866.07,1832.92,1743.93$ & $1868.79,1832.60,1743.59$ & $-\mathrm{C}=\mathrm{O}$ in carbonyl, carboxyl groups, and lactones \\
\hline 4 & 1691.47 & 1691.51 & $-\mathrm{C}=\mathrm{O}$ in quinine or quinone \\
\hline 5 & $1644.47,1517.28,1425.74,1393.18$ & $1644.14,1516.82,1426.50,1391.95$ & $\begin{array}{l}-\mathrm{C}=\mathrm{C}-\text { in aromatic rings, }-\mathrm{C}=\mathrm{O} \text { in highly conjugated } \\
\text { carbonyl groups, and }-\mathrm{C}-\mathrm{H} \text { deformations in Alkanes }\end{array}$ \\
\hline 6 & $1339.81,1187.65,1146.36,1078.53$ & $1360.57,1223.45,1079.16,1040.23$ & $\begin{array}{l}\text {-C-O- in alcohols, phenols, ethers, esters, acids, epoxides, lactones, } \\
\text { and carboxylic anhydrides }\end{array}$ \\
\hline 7 & $875.55,830.19,744.37,695.57$ & $871.09,831.03,758.74,695.74$ & $\begin{array}{l}-\mathrm{C}-\mathrm{C}-\text { deformations and out of plane }-\mathrm{C}-\mathrm{H} \text { deformations in } \\
\text { aromatic rings }\end{array}$ \\
\hline
\end{tabular}



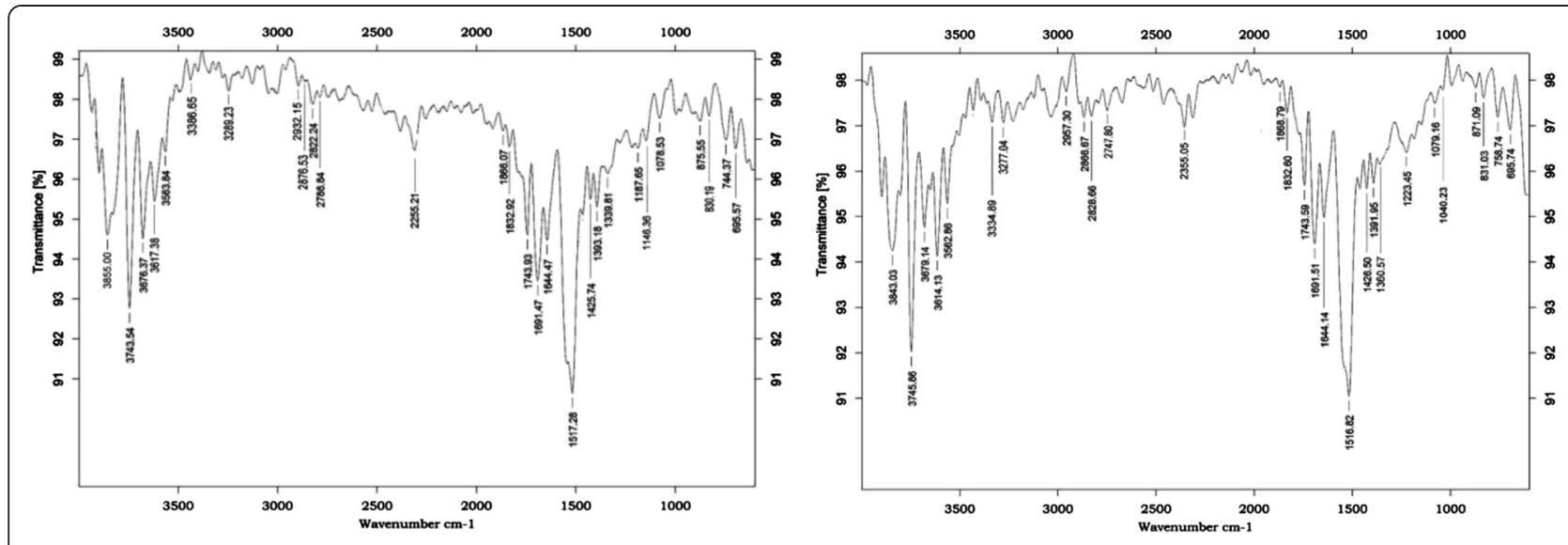

Figure 6 FTIR spectra of NVNC before and after fluoride adsorption.

Rochester 1990b, 1990c) have been noted. The absence of specific peak pertains to -C-F, suggesting that the adsorption process was physisorption but not chemisorptions. The shifts or decrease in the percentage of transmittance in FTIR spectra before and after deflouidation in the range 4,000 to $500 \mathrm{~cm}^{-1}$ (Figure 6 and
Table 5) indicates that the sorption of fluoride on the surface of the adsorbent is through physisorption.

\section{SEM analysis of NVNC before and after defluoridation}

SEM micrographs were studied for surface and morphological characteristics of activated carbon material
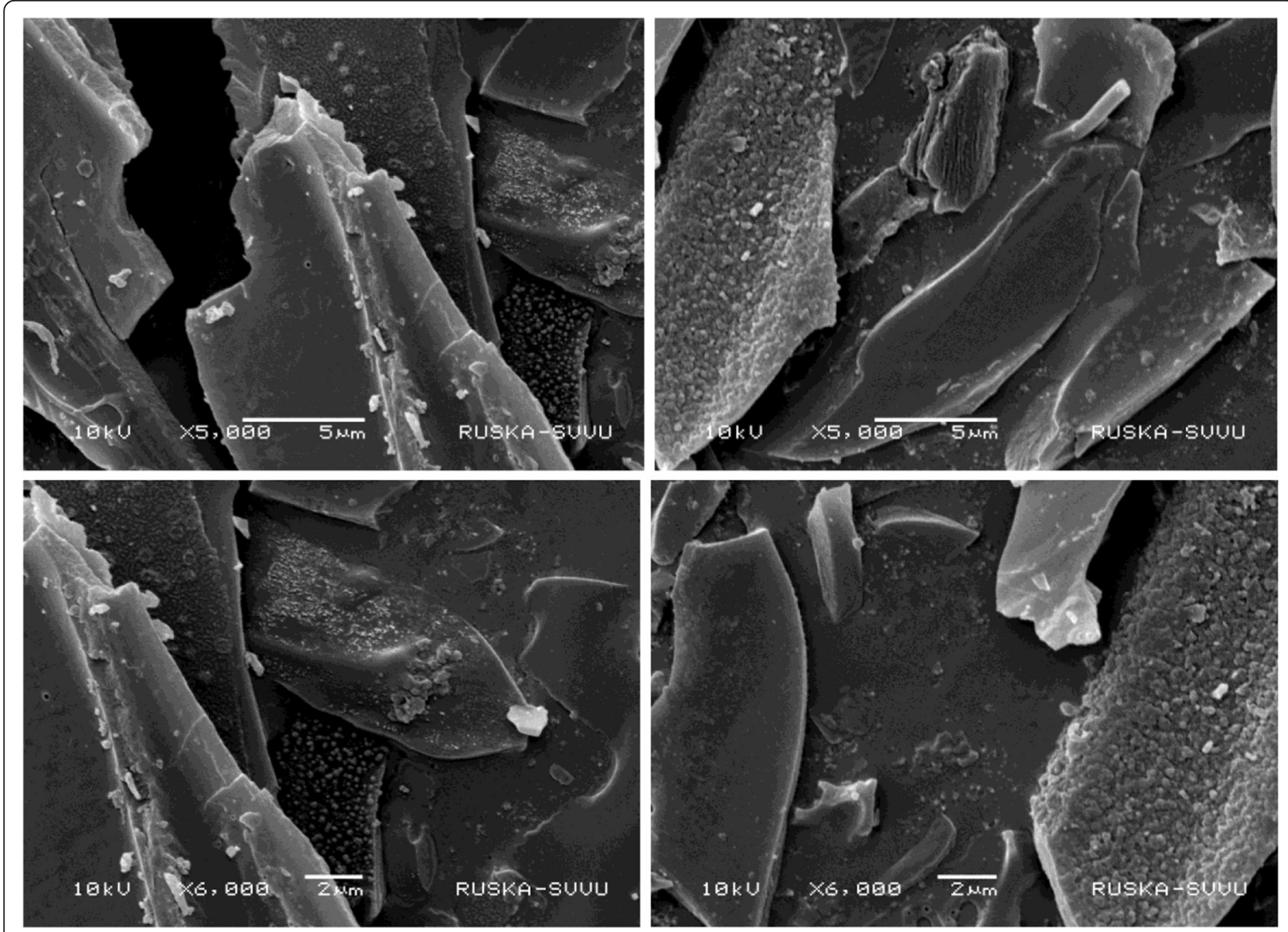

Figure 7 SEM analysis of NVNC before (left) and after (right) defluoridation at $\times 5,000$ and $\times 6,000$ magnifications. 


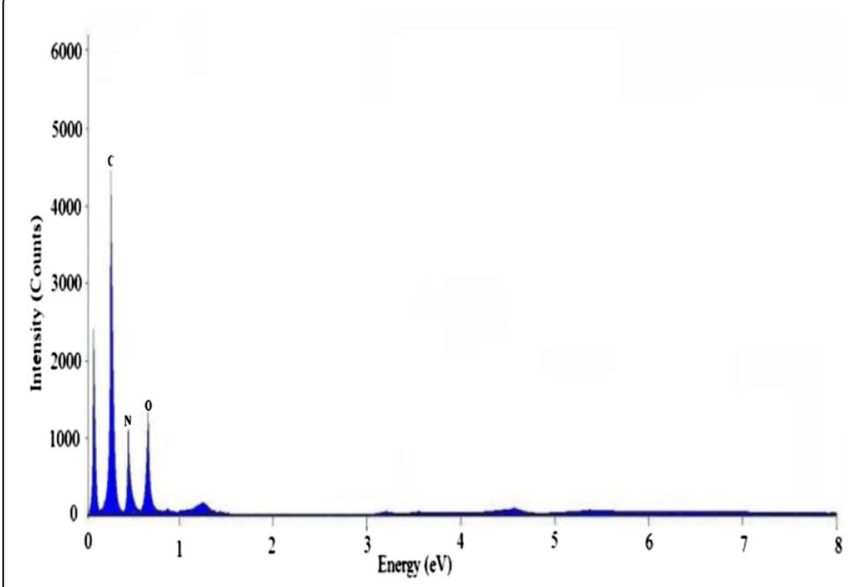

Figure 8 The EDX spectra of NVNC before and after defluoridation.

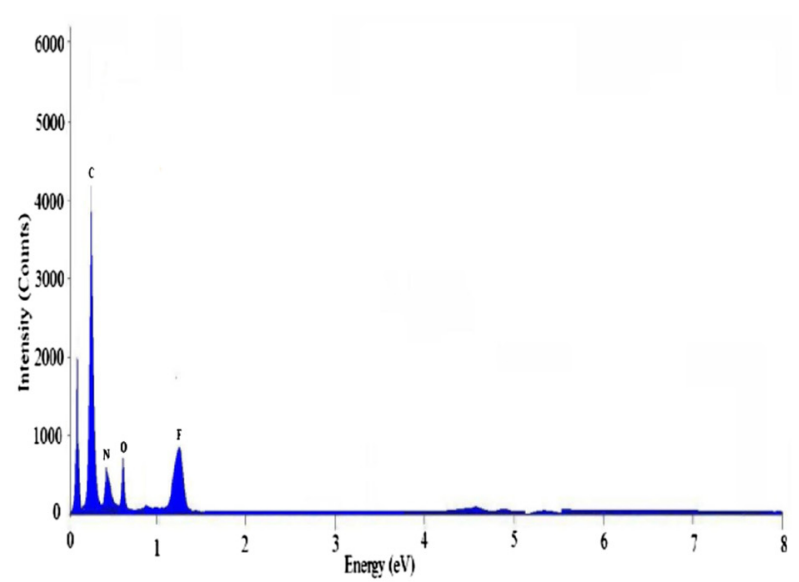

(vide Figure 7). The examination of the SEM micrographs of the activated carbon material showed that in micrographs, dark areas indicated pores and grey areas indicated the carbon matrix and showed rough surface of the adsorbent that provided large surface area for adsorption. Overall, a well-developed porous surface was observed at higher magnification, and further, randomly distributed pore size was observed in all micrographs. The grey surface area of every micrograph contained smaller microparticles ( $\mathrm{nm}$ to $\mu \mathrm{m}$ ) which might be due to the activated sites or surface functional groups of the carbon. The adsorption of fluoride might be due to the presence of pores and active groups on the surface. SEM micrographs proved the fluoride adsorption.

\section{EDX elemental analysis}

The EDX elemental analysis highlighted the presence of carbon and oxygen ions in untreated and fluoride treated sample (Figure 8 and Table 6). Nitrogen is also present but in less mass amount compared with carbon and oxygen. The intensity of the fluoride signals was higher in samples treated with fluoride and was below the limit of detection on the untreated samples. It can clearly conclude that the oxygen element concentration has been reduced after adsorption process, but simultaneously, fluoride concentration is increased in the adsorbent and hence the fluoride ion may replace the ion-containing oxygen atom $\left(\mathrm{OH}^{-}\right)$on the surface of adsorbent.

\section{Comparison with other carbon adsorbents}

The efficiency of the adsorbent developed in this work, viz., NVNC has been compared with the already existing adsorbents reported in the literature based on the adsorbent mass needed to reduce the fluoride concentration from $4 \mathrm{mg} / \mathrm{l}$ (average of fluoride concentration in potable water) to $1 \mathrm{mg} / \mathrm{l}$ which is a reasonable concentration for health standards. In this concern, the amount of adsorbent has been estimated using a mass balance equation (Ramos et al. 1999):

$$
V C_{\mathrm{i}}=m q+V C_{\mathrm{e}}
$$

because $q$ and $C_{\mathrm{e}}$ must be in equilibrium, $q$ for adsorbents can be calculated using Langmuir equation, and $C_{\mathrm{i}}, C_{\mathrm{e}}$, and $V$ are $4,1 \mathrm{mg} / \mathrm{l}$, and $1 \mathrm{~m}^{3}$ (1,000 liters), respectively. The results and also the values pertaining to the other active carbons reported in literature have been presented in the Table 7.

From the table, it may be noted that the active carbon developed in this work, namely, NVNC is more effective than commercially available F-4000 carbon and also than many other active carbons reported in literature such as $A$. farnesiana fruits carbon, T. angustata plant carbon, Lagenaria siceraria shell carbon, and aluminum-impregnated carbon. Though $\mathrm{KMnO}_{4}$-modified carbon prepared from rice straw, aluminum-supported carbon nanotubes, and carbons loaded with specific chemical moieties pecan nut shells (CMPNS) seem to be scoring better than NVNC, they have their inherent disadvantages. In the case of

Table 6 Elemental analysis of NVNC by EDX spectra before and after defluoridation

\begin{tabular}{llllllllllll}
\hline & \multicolumn{3}{c}{ Elemental analysis (EDX) (before) } & & & \multicolumn{3}{c}{ Elemental analysis (EDX) (after) } \\
\hline Composition & CK & NK & OK & FK & Total & & CK & NK & OK & FK & Total \\
\hline Energy (eV) & 0.3 & 0.5 & 0.6 & 1.1 & & & 0.3 & 0.5 & 0.6 & 1.1 \\
Wt.\% (mass ratios) & 84.3 & 3.0 & 12.7 & - & 100 & & 84.1 & 1.1 & 10.1 & 4.7 & 100 \\
At.\% (atomic percentages) & 84.6 & 2.9 & 12.5 & - & 100 & & 85.1 & 0.9 & 9.8 & 4.2 & 100 \\
\hline
\end{tabular}


Table 7 Comparison study with other carbon adsorbents

\begin{tabular}{|c|c|c|c|c|c|c|c|}
\hline Serial No. & Adsorbent & $\mathrm{pH}$ & $\mathrm{Ci}(\mathrm{mg} / \mathrm{l})$ & $q_{e}(m g / g)$ & $\mathrm{V} / \mathrm{m}(\mathrm{l} / \mathrm{g})$ & m (kg) & Reference \\
\hline 1 & KMnO4 modified carbon prepared from rice straw & 2.0 & 5 to 20 & 3.40 & 1.13 & 0.89 & Daifullah et al. (2007) \\
\hline 2 & Aluminum impregnated carbon & 4.0 & 0.5 to 15 & 1.006 & 0.34 & 2.98 & Ramos et al. (1999) \\
\hline 3 & Alumina supported carbon nanotubes & 6.0 & 1 to 50 & 9.68 & 3.20 & 0.31 & Li et al. (2001) \\
\hline 4 & Acacia farnesiana fruits Carbon & 7.0 & 1.5 to 15 & 0.333 & 0.121 & 4.50 & Hanumantharao et al. (2012b) \\
\hline 5 & $\begin{array}{l}\text { CMPNS (carbons loaded with specific chemical } \\
\text { moieties pecan nut shells) }\end{array}$ & 7.0 & 5 to 40 & 2.3 & 0.7667 & 1.30 & Montoya et al. (2012) \\
\hline 6 & $\begin{array}{l}\text { Commercially available F- } 400 \text { carbon (produced } \\
\text { from coconut shells by Calgon Corporation) }\end{array}$ & $6.2-7.5$ & 0.5 to 15 & 0.0741 & 0.025 & 40.50 & Ramos et al. (1999) \\
\hline 7 & Typha angustata plant carbon & 7.0 & 1.5 to 15 & 0.429 & 0.121 & 3.50 & Hanumantharao et al. (2012a) \\
\hline 8 & Lagenaria siceraria shell carbon & 7.0 & 1.5 to 15 & 0.375 & 0.122 & 4.00 & Hanumantharao et al. (2012c) \\
\hline 9 & NVNC & 7.0 & 1 to 12 & 1.150 & 0.3833 & 2.61 & Present work \\
\hline
\end{tabular}

$\mathrm{KMnO}_{4}$-modified carbon from rice straw, the optimum $\mathrm{pH}$ condition is 2 which is a limiting factor for its application to defluoridation of drinking water. In view of the availability of plenty of raw material, the ease of deriving the active carbons and, further, the simplicity of the technique make the NVNC better than the rest two.

Further, it may be noted that the values of various physicochemical properties of NVNC have been found

Table 8 Fluoride ion concentration (before and after defluoridation) of ground water samples

\begin{tabular}{|c|c|c|c|c|}
\hline \multirow[t]{2}{*}{ Sample number } & \multirow[t]{2}{*}{ Village name } & \multirow[t]{2}{*}{$C_{i}(\mathrm{mg} / \mathrm{l})$ (before defluoridation) } & $C_{f}(m g / l)$ (after defluoridation) & $\%$ Removal \\
\hline & & & \multicolumn{2}{|l|}{ With NVNC } \\
\hline 1 & Sivapuram & 3.75 & 0.454 & 87.9 \\
\hline 2 & Koppukonda & 3.82 & 0.554 & 85.5 \\
\hline 3 & Thimmayapalem & 3.56 & 0.495 & 86.1 \\
\hline 4 & Narasayapalem & 3.48 & 0.432 & 87.6 \\
\hline 5 & Brahmanapalli & 4.27 & 0.743 & 82.6 \\
\hline 6 & Mada manchipadu & 3.88 & 0.442 & 88.6 \\
\hline 7 & Andugulapadu & 3.69 & 0.432 & 88.3 \\
\hline 8 & Tsouta palem & 4.09 & 0.483 & 88.2 \\
\hline 9 & Venkupalem & 3.37 & 0.377 & 88.8 \\
\hline 10 & Nagulavaram & 3.28 & 0.538 & 83.6 \\
\hline 11 & Peda kancherla & 3.68 & 0.545 & 85.2 \\
\hline 12 & Narasarayani palem & 3.52 & 0.538 & 84.7 \\
\hline 13 & Dondapadu & 3.95 & 0.545 & 86.2 \\
\hline 14 & Vinukonda & 3.62 & 0.391 & 89.2 \\
\hline 15 & Gokana konda & 4.21 & 0.531 & 87.4 \\
\hline 16 & Enugupalem & 3.69 & 0.523 & 85.7 \\
\hline 17 & Surepalli & 3.45 & 0.521 & 84.9 \\
\hline 18 & Ummadivaram & 3.59 & 0.582 & 83.8 \\
\hline 19 & Perumalla palli & 4.12 & 0.655 & 84.1 \\
\hline 20 & Nayanipalem & 3.68 & 0.592 & 83.9 \\
\hline 21 & Settupalli & 3.72 & 0.513 & 86.2 \\
\hline 22 & Vithamrajupalli & 3.43 & 0.579 & 83.1 \\
\hline 23 & Neelagangavaram & 3.49 & 0.520 & 85.1 \\
\hline
\end{tabular}


to be comparable with the other activated carbons, i.e., the moisture content value with the activated carbons of Euphorbia antiquorum L. (Palanisamy and Sivakumar 2008), loss on ignition value with the activated Kaza's carbons (Sreenivasa Rao et al. 2011), ash content value with the activated carbon of bituminous coal (Cuhadaroglu and Aydemir Uygun 2008), $\mathrm{pH}$ value with the activated carbons of E. Antiquorum L. (Palanisamy and Sivakumar 2008) and coconut shell (Gimba and Turoti 2006), and the basicity values with the activated carbon prepared from rice straw (Daifullah et al. 2007).

Moreover, the calculated BET surface area value for the adsorbent, NVNC, has been found to be $262.6 \mathrm{~m}^{2} / \mathrm{g}$ which is more than some other active carbons such as L. siceraria shell carbon $\left(198.5 \mathrm{~m}^{2} / \mathrm{g}\right)$ (Hanumantharao et al. 2012c), peanut hull $\left(208 \mathrm{~m}^{2} / \mathrm{g}\right)$ (Periasamy and Namasivayam 1994), and cassava peel $\left(200 \mathrm{~m}^{2} / \mathrm{g}\right)$ (Rajeshwari et al. 2001), and hence, NVNC shows more adsorption capacity than the said active carbons.

It may be inferred from this discussion that the prepared carbon, NVNC, exhibits considerably greater fluoride adsorption potential when compared with some of the less attractive and low-cost materials.

\section{Applications}

The adoptability of the methodology developed with the new bio-sorbent in this work for removing fluoride has been tried with some real water samples collected from groundwaters in fluoride-affected areas in Vinukonda Mandal of Guntur District of Andhra Pradesh.

The samples were subjected to extraction for fluoride using the said bio-sorbents developed in this work at optimum conditions of $\mathrm{pH}$, equilibration time, and sorbent concentration. The results obtained were presented in Table 8.

From Table 8, it is evident that the concentration of fluoride in all groundwater samples collected from various villages of Vinukonda Mandal, Guntur District have been varied from 3.37 to $4.27 \mathrm{mg} / \mathrm{l}$. The data indicates that most of the samples contain excess of fluoride beyond the permissible World Health Organization limit $1.5 \mathrm{mg} / \mathrm{l}$ (WHO 1984, 2004; BIS 1991). Hence, in the present work, the defluoridation studies were carried out on these particular samples using the adsorbent, NVNC, in order to reduce the fluoride content below the permissible limit. The concentrations of fluoride ion in these samples after defluoridation were analyzed and reported in Table 8.

It may be inferred that NVNC effectively decrease the fluoride content in groundwater samples to below permissible limits under optimum experimental conditions.

It can be inferred from Table 8 that the methodology developed in this research work using active carbon NVNC is remarkably successful.

\section{Conclusions}

A new activated carbon adsorbent has been developed for fluoride removal from aqueous solution in this study. The results indicated that the maximum fluoride adsorption takes place at the optimum $\mathrm{pH}$ of 7.0, the adsorbent dosage of $4.0 \mathrm{~g} / \mathrm{l}$, equilibration time of $50 \mathrm{~min}$, and at a temperature of $30^{\circ} \mathrm{C} \pm 1^{\circ} \mathrm{C}$.

It was observed that the adsorption process satisfactorily fitted with Langmuir adsorption isotherm which had good correlation coefficient value indicating monolayer adsorption and also confirmed the heterogeneous surface of the adsorbent due to Freundlich isotherm. The Temkin and Dubinin-Radushkevich isotherms also established the linear relationship which indicated the applicability of these two adsorption isotherms and confirmed the heterogeneous surface of the adsorbent. The Dubinin-Radushkevich mean free energy, $E$, was found to be $7.07 \mathrm{~kJ} / \mathrm{mol}$ for the activated carbon adsorbent NVNC. An energy value of $<8 \mathrm{kJmol}^{-1}$ was an indication of physisorption. Hence, adsorption is not restricted to monolayer coverage as purposed for chemisorption.

In kinetic studies of defluoridation, pseudo-first-order, pseudo-second-order, Weber and Morris intraparticle diffusion model, Bangham's pore diffusion model, and Elovich equations were applied to identify the rate and kinetics of adsorption process. The adsorption process had good correlation coefficient values with pseudo-second-order, Bangham's pore diffusion, and Elovich equations which indicated that the process fitted with pseudo-second-order model and pore diffusion played a very important role in controlling the rate of the reaction. Even though the plots of Weber and Morris intraparticle diffusion made straight lines with correlation coefficients, they fail to pass through origin. This indicated that the process of the mechanism of adsorption was complex in nature with the more than one mechanism limiting the rate of adsorption, i.e., particle diffusion of fluoride adsorption was more towards the rate controlling step than intraparticle diffusion model. The FTIR studies indicated the participation of the surface sites of the adsorbent in the adsorbent interaction. Characterization of the activated carbon adsorbent through FTIR and SEM-EDX techniques confirmed the adsorption of the fluoride ion on the adsorbent surface. The active carbon developed has been found to be effectively decreasing the fluoride content in real groundwater samples below the permissible limits, and hence, the active carbon NVNC can be successfully applied in wastewater treatment technologies in controlling the fluorides.

\section{Author details}

'Department of Chemistry, Acharya Nagarjuna University, 522510 Guntur Dt., AP, India. ${ }^{2}$ Department of Chemistry, K L University, Vaddeswaram, 522502 Guntur Dt., AP, India.

Received: 15 June 2014 Accepted: 30 November 2014 Published online: 18 April 2015 


\section{References}

Adikari SK, Tipnis UK, Harkare WP, Govindan KP (1989) Defluoridation during desalination of brackish water by electrodialysis. Desalination 71:301-312

Akbar E, Maurice SO, Aoyi O, Shigeo A (2008) Removal of fluoride ions from aqueous solution at low $\mathrm{pH}$ using schwertmannit. J Hazard Mater 152:571-579

Alagumuthu G, Rajan M (2010a) Kinetic and equilibrium studies on fluoride removal by zirconium (IV)-impregnated ground nutshell carbon. Hem Ind 64(4):295-304

Alagumuthu G, Rajan M (2010b) Equilibrium and kinetics of adsorption of fluoride onto zirconium impregnated cashew nut shell carbon. Chem Eng J 158:451-457

Alagumuthu G, Veeraputhiran V (2011) Sorption Equilibrium of fluoride onto Phyllanthus emblica activated carbon. Int J Res Chem Environ 1(1):42-47

Alagumuthu G, Veeraputhiran V, Venkataraman R (2011) Fluoride sorption using Cynodon dactylon based activated carbon. Hem Ind 65(1):23-35

Aldaco R, Garea A, Irabien A (2007) Calcium fluoride recovery from fluoride Waste water in a fluidized bed reactor. Water Res 41:810-818

Amer Z, Bariou B, Mameri N, Taky M, Nicolas S, Elimidaoui A (2001) Fluoride removal from brakish water by electro dialysis. Desalination 133:215-223

Apambire WB, Boyle DR, Michel FA (1997) Geochemistry, genesis and health implications of fluoriferous groundwaters in the upper regions of Ghana. Environ Geol 33:13-24

APHA (American Public Health Association) (1985) Standard methods for the Examination of Water and Waste water. APHA, Washington, DC

Arulanantham AJ, Krishna TR, Balasubramanium (1989) Studies on fluoride removal by coconut shell carbon. Ind J Environ Health 13:531

ASTM D4607-94 (2006) Standard test method for Determination of lodine number of Activated Carbon

Atkins P (1999) Physical chemistry, 6th edn. Oxford University Press, London, pp 857-864

Attia AA, Rashwan WE, Khedr SA (2006) Capacity of activated carbon in the removal of acid dyes subsequent to its thermal treatment. Dyes Pigments 69:128-136

Ayoob S, Gupta AK (2006) Fluoride in drinking water: A review on the status and tress effects. Environ Sci Technol 36:433-487

Ayoob S, Gupta AK (2008) Insights into isotherm making in the sorptive removal of fluoride from drinking water. J Hazard Mater 152:976-985

Bandosz TJ, Jagiello J, Schwarz JA (1992) A comparison of methods to asses surface acidic groups on activated carbons. Anal Chem 64:891-895

Barbier O, Arreola-Mendoza L, Del Razo LM (2010) Molecular mechanisms of fluoride Toxicity. Chem Biol Interact 188:319-333

Biniak S, Szymanski G, Siedlewski J, Swiatkowski A (1997) The characterization of activated carbons with oxygen and nitrogen surface groups. Carbon 35 (12):1799-1810

BIS (1991) Indian Standards for Drinking Water-Specification. Bureau of Indian Standards, New Delhi

BIS (Bureau of Indian Standards) (1989) Activated Carbon, Powdered and Granular-Methods of sampling and its tests. BIS, New Delhi, p 877

Boehm HP (1994) Some aspects of the surface chemistry of carbon blacks and others carbons. Carbon 32:759-769

Bouberka Z, Kaoha S, Kamecha, Elmaleh S, Derriche Z (2005) Sorption study of an acid dye from an aqueous solutions using modified clays. J Hazard Mater 119:117-124

Brunauer S, Emmett PH, Teller E (1938) Adsorption of Gases in Multimolecular Layers. J Am Chem Soc 60:309-315

Budinova T, Ekinci E, Yardim F, Grimm A, Bjornbom E, Minkova V, Goranova M (2006) Characterization and application of activated carbon produced by $\mathrm{H}_{3} \mathrm{PO}_{4}$ and water vapor activation. Fuel Process Techonol 87:899-905

Castel C, Schweizer M, Simonnot MO, Sardin M (2000) Selective removal of fluoride ions by a two-way ion-exchange cyclic processes. Chem Eng Sci 55:3341-3352

Cengeloglu Y, Esengul K, Ersoz M (2002) Removal of Fluoride from aqueous solution by using red mud. Sep Pur Technol 28:81-86

Chaturvedi AK, Yadva KP, Yadava KC, Pathak KC, Singh VN (1990) Defluoridation of water by adsorption on fly ash. Water Air Soil Pollut 49(1-2):51-61

Chauhan VS, Dwivedi PK, lyengar L (2007) Investigations on activated alumina based domestic defluoridation units. J Hazard Mater 139:103-107

Chinoy NJ (1991) Effects of fluoride on physiology of animals and human beings. Indian J Environ Toxicol 1:17-32

Chubar NI, Samanidou VF, Kouts VS, Gallios GG, Kanibolotsky VA, Strelko W, Zhuravlev IZ (2005) Adsorption of fluoride, chloride, bromide and bromate ions on a novel ion exchange. J Colloid Interface Sci 291:67-74
Cuhadaroglu D, Aydemir Uygun O (2008) Production and characterization of activated carbon from a bituminous coal by chemical activation. African $J$ Biotech 7(20):3703-3710

Daifullah AAM, Girgis BS, Gad HMH (2003) Utilization of agro-residues (rice husk) in small waste water treatment plans. Mater Lett 57:1723-1731, http://www sciencedirect.com/science/article/pii/S0167577X02010583

Daifullah AAM, Yakout SM, Elreefy SA (2007) Adsorption of fluoride in aqueous solutions using $\mathrm{KMnO}_{4}$ modified activated carbon derived from steam pyrolysis of rice straw. J Hazard Mater 147:633-643

Dieye A, Larchet C, Auclair B, Mar-Diop C (1998) Elimination des fluorures parla dialyse ionicque croisee. Eur Polym J 34:67-75

El-Hendawy ANA (2003) Influence of $\mathrm{HNO}_{3}$ oxidation on the structure and adsorptive properties of corncob-based activated carbon. Carbon 41:713-722

El-Hendawy ANA, Samra SE, Girgis BS (2001) Adsorption characteristics of activated carbons obtained from corncobs. Colloids Surf A Physicochem Eng Aspects 180:209-221

Fanning PE, Vannice MA (1993) A DRIFTS study of the formation of surface groups on carbon by oxidation. Carbon 31(5):721-730

Fawell J, Bailey K, Chilton J, Dahi E, Fewtrell L, Magara Y (2006) Fluoride in drinking water. WHO IWA Publishing, London-Seattle

Feng Shen X, Chen PG, Guohua C (2003) Electrochemical removal of fluoride ions from industrial wastewater. Chem Eng Sci 58:987-993

Figueiredo JL, Perria MFR, Freitas MMA, Orfao JJM (1999) Modification of the surface chemistry of activated carbons. Carbon 37(9):1379-1389

Ganvir V, Das K (2011) Removal of Fluoride from Drinking Water Using Aluminum Hydroxide Coated Rice Husk Ash. J Hazard Mater 185(2-3):1287-1294

Garmes H, Persin F, Sandeaux J (2002) Defluoridation of groundwater by a hybrid process combining adsorption and Donnan dialysis. Desalination 145:287-291

Gazzano E, Bergandi L, Riganti C, Aldieri E, Doublier S, Costamagna C, Bosia A Ghigo D (2010) Fluoride effects: the two faces of Janus. Curr Med Chem $17: 2431-2441$

Gimba A, Turoti A (2006) Adsorption efficiency of coconut shell-based activated carbons on colour of molasses. SWJ 1(1):21-26

Girgis BS, El-Hendawy ANA (2002) Porosity development in activated carbons obtained from date pits under chemical activation with phosphoric acid. Microporous Mesoporous Mater 52:105-117

Goldberg S, Sposito G (1984a) A chemical model of phosphate adsorption by soils: 1. Reference oxide minerals. Soil Sci Soc Am J 48:772-778

Goldberg S, Sposito G (1984b) A chemical model of phosphate adsorption by soils: II. Noncalcareous soils. Soil Sci Soc Am J 48:779-783

Gomez-Serrano V, Acedo-Ramos M, Lopez-Peinado AJ, Venezuela-Calahorro C (1994) Study of Surface Functional Groups by FT-IR. Fuel 73(3):387-395

Grynpas MD, Chachra D, Limeback H (2000) In: Henderson JE, Goltzman D (eds) The Action of Fluoride on Bone, The Osteoporosis Primer. Cambridge University Press, Cambridge, UK

Hall KR, Eagleton LC, Acrivos A, Vermevlem T (1966) Pore and solid diffusion kinetics in fixed bed adsorption under constant pattern conditions. Indian Eng Chem Fundam 5:212-219

Hanumantharao Y, Kishore M, Ravindhranath K (2012a) Characterization and Defluoridation Studies of Active Carbon Derived from Typha Angustata Plants. J Analytical Sci Technol 3(2):167-181

Hanumantharao Y, Kishore M, Ravindhranath K (2012b) Characterization and defluoridation studies using activated Acacia Farnesiana carbon as adsorbent. Ele J Environ Agric Food Chem 11(5):442-458

Hanumantharao Y, Kishore M, Ravindhranath K (2012c) Characterization and adsorption studies of Lagenaria siceraria shell carbon for the removal of fluoride. Inter J Chem Tech Res 4(4):1686-1700

Hashim MA (ed) (1994) Symposium on Bioproducts Processing-Technologies for the Tropics, Kuala Lumpur, Malaysia. INST Chemical Engineers, UK

Hichour M, Persin F, Molenat J, Sandeaux J, Gavach C (1999) Fluoride removal from diluted solutions by Donnan dialysis with anion exchange membranes. Desalination 122:53-62

Hichour M, Persin F, Sandeaux J, Gavach C (2000) Water defluoridation by Donann Dialysis and electro dialysis. Sep Purif Technol 18:1-11

Hill A, Marsh H (1968) A study of the adsorption of iodine and acetic acid from aqueous solutions on characterized porous carbons. Carbon $6(l): 31-39$

Horsfall M, Spiff A (2005) Effects of temperature on the sorption of Pb2+ and Cd2+ from aqueous solution by Caladium bicolor (Wild Cocoyam) biomas. J Biotechnol 8:162-169 
Hu CY, Lo SL, Kuan WH (2003) Effect of co-exiting anions on fluoride removal in electrocoagulation process using aluminium electrodes. Water Res $37: 4513-4523$

Ibrahim DM, El-Hemaly SA, Abdel-Kerim FM (1980) Study of rice-husk ash silica by infrared spectroscopy. Thermo Chimica Acta 37:307-314

Ishizaki C, Marti I (1981) Surface oxide structures on a commercial activated carbon. Carbon 19:409-412, http://www.sciencedirect.com/science/article/pii/ 0008622381900233

Jackson D, Murray JJ, Fairpo CG (1973) Lifelong benefits of fluoride in drinking water. Br Dental J 134(10):419-422

Ji Y, Li T, Li Z, Wang X, Liu Q (2007) Preparation of activated carbons by microwave heating $\mathrm{KOH}$ activation. Appl Surf Sci 254(2):506-512

Kadirvelu K, Faur-Brasquet C, Le Cloirec P (2000) Removal of Cu (II), Pb(II), and Ni (II) by Adsorption onto Activated Carbon Cloths. Langmuir 16:8404-8409

Karthikeyan G, Siva Elango S (2007) Fluoride sorption using Morringa Indicabased activated carbon. Iran J Environ Health Sci Eng 4(1):21-28

Kishore M, Hanumantharao Y (2011) Preparation and development of adsorbent carbon from Acacia farnesiana for defluoridation. Int J Plant Animal Environ Sci 1(3):209-223

Kumar JV, Moss ME (2008) Fluorides in dental public health programs. Dent Clin North Am 52:387-401

Lagergren S (1898) About the theory of so-called adsorption of soluble substances. Kungliga Svenska, Vetenskapsakademiens, Handlingar 24(4):1-39

Lahnid S, Tahaikt M, Elaroui K, Idrissi I, Hafsi M, Laaziz I, Amor Z, Tiyal F, Elmidaoui A (2008) Economic evaluation of fluoride removal by electrodialysis. Desalination 230:213-219

Lapuente R, Cases F, Garces P, Morallon E, Vazquez JL (1998) A voltammeter and FTIR-ATR study of the electro polymerization of phenol on platinum electrodes in carbonate medium: Influence of sulfide. J Electroanal Chem 451:163-171

Lhassani A, Rumeau M, Benjelloun D, Pontie M (2001) Selective demineralization of water by nanofiltration application to the defluoridation of brackish water. Water Res 35:3260-3264

Li YH, Wang S, Cao A, Zhao D, Zhang X, Xu C, Luan Z, Ruan D, Liang J, Wu D, Wei B (2001) Adsorption of fluoride from water by amorphous alumina supported on carbon nanotubes. Chem Phys Lett 350(5\&6):412-416

Liu J, Xu Z, Li X, Zhang Y, Zhou Y, Wang Z, Wang X (2007) An Improved process to prepare high separation performance PA/PVDF hollow fiber composite nano filtration membranes. Sep Purif Technol 58:53-60

Lounici H, Addour L, Belhocine D, Grib H, Nicolas S, Bariou B (1997) Study of a new technique for fluoride removal from water. Desalination 114:241-25

Maheshwari RC, Meenakshi (2006) Fluoride in drinking water and its removal. J Hazard Mater 137(1):456-463

Mameri N, Lounici H, Belhocine D, Grib H, Prion DL, Yahiat Y (2001) Defluoridation of Sahara Water by small electro coagulation using bipolar Aluminium Electrodes. Sep Purif Technol 24:113-119

Marsh H, Rodriguez-Reinoso F (2006) Activated Carbon, Elsevier Science \& Technology Books., pp 401-462

McKee RH, Jhonston WS (1934) Removal of fluorides from drinking water. Ind Eng Chem 26(8):849-850

Meenakshi S, Viswanathan N (2007) Identification of selective ion-exchange resin for fluoride sorption. J Colloid Interface Sci 308:438-450

Meldrum BJ, Rochester CH (1990a) In Situ Infrared Study of the Surface Oxidation of Activated Carbon Dispersed in Potassium Bromide. J Chem Soc Faraday Trans 86:2997-3002

Meldrum BJ, Rochester CH (1990b) In situ infrared study of the surface oxidation of activated carbon in oxygen and carbon dioxide. J Chem Soc Faraday Trans 86(5):861-865

Meldrum BJ, Rochester CH (1990c) In situ infrared study of the modification of the surface of activated carbon by ammonia, water and hydrogen. J Chem Soc Faraday Trans 86(10):1881-1884

Menkouchi SMA, Annouar S, Tahaikt M (2007) Fluoride Removal for Underground Brackish Water by Adsorption on the Natural Chitosan and by Electrodialysis. Desalination 212:37

Mjengera H, Mkongo G (2003) Appropriate defluoridation technology for use in fluorotic areas in Tanzania. Phys Chem Earth 28:1097-1104

Mohan D, Sharma R, Vinod K, Singh PS, Pittman CU Jr (2012) Fluoride Removal from Water using Bio-Char, a Green Waste, Low-Cost Adsorbent: Equilibrium Uptake and Sorption Dynamics Modeling. Ind Eng Chem Res 51:900-914
Mohapatra D, Mishra D, Mishra SP, Roy Chaudhury G, Das RPJ (2004) Use of oxide minerals to abate fluoride from water. Colloid Interface Sci 275:355-359

Monika J, Garg V, Kadirvelu K (2009) Chromium (VI) removal from aqueous solution, using sunflower stem waste. J Hazard Mater 162:365-372

Montoya VH, Montoya LAR, Petriciolet AB, Moran MAM (2012) Optimizing the removal of fluoride from water using new carbons obtained by modification of nut shell with a calcium solution from egg shell. Biochem Eng J 62:1-7

Moreno-Castilla C, Carrasco-Marın F, Maldonado-Hodar FJ, Rivera-Utrilla J (1998) Effects of non-oxidant and oxidant acidtreatments on the surface properties of an activated carbonwith very low ash content. Carbon 36(1-2):145-151

Nageswara Rao M, Chakrapani CH, Rajeswara Reddy BV, Suresh Babu CH, Hanumantha Rao Y, Somasekhara Rao K, Rajesh K (2011) Preparation of activated kaza's carbons from bio-materials and their characterization. Int J Appl Biol Pharm Tech 2(3):610-618

Namasivayam C, Kadirvelu K (1994) Coir pith, an agricultural waste by-product, for the treatment of dyeing waste water. Biores Technol 48:79-81

Namasivayam C, Kadirvelu K (1997) Agricultural solid wastes for the removal of heavy metals: Adsorption of $\mathrm{Cu}(\mathrm{II})$ by coir pith carbon. Chemosphere 34:377-399

Nawlakhe WG, Kulkarni DN, Pathak BN, Bulusu KR (1975) De-fluoridation of water by Nalgonda technique. Ind J Environ Health 17:26-65

Newcombe G, Hayes R, Drikas M (1993) Granular activated carbon: importance of surface properties in the adsorption of naturally occurring organics. Colloids Surf A:Physicochem Eng Aspects 78:65-71

Onyango MS, Kojima Y, Aoyi O, Bernardo EC, Matsuda H (2004) Adsorption equilibrium modeling and solution chemistry dependence of fluoride removal from water by trivalent-cation-exchanged zeolite F-9. J Colloid Interface Sci 279(2):341-350

Onyango MS, Matsuda H, Alain T (2006) Chapter 1: Fluoride Removal from Water Using Adsorption Technique. Adv Fluorine Sci 2:1

Ozgul G, Adnan O, Safa Ozcan A, Ferdi Gercel H (2007) Preparation of activated carbon from a renewable bio-plant of Euphorbia rigida by $\mathrm{H} 2 \mathrm{SO} 4$ activation and its adsorption behavior in aqueous solutions. Appl Surf Sci 253:4843-4852, http://www.sciencedirect.com/science/article/pii/S0169433206013900

Painter P, Starsinic M, Coleman M (1985) Determination of functional groups in coal by Fourier transform interferometry. In: Fourier transform infrared spectroscopy, 4th edn. Academic Press, New York, pp 169-189

Palanisamy PN, Sivakumar P (2008) Production and Characterization of a novel non-conventional low-cost adsorbent from Euphorbia Antiquorum $L$ Rasayan J Chem 1(4):901-910

Park SH, McClain S, Tian ZR, Suib SL, Karwacki C (1997) Surface and bulk measurements of metals deposited on activated carbon. Chem Mater 9:176-183

Periasamy K, Namasivayam C (1994) Process development for removal and recovery of cadmium from wastewater by a low-cost adsorbent: adsorption rates and equilibrium studies. Ind Eng Chem Res 33:317-320

Puziy I, Poddubnaya O, Martinez-Alonso A, Suarez- Garcia F, Tascon J (2003) Synthetic carbons activated with phosphoric acid III. Carbons prepared in air. Carbon 41:1181-1191

Raichur AM, Jyoti Basu M (2001) Adsorption of fluoride onto mixed rare earth Oxides. Sep Purif Technol 24:121-127

Rajeshwari S, Sivakumar S, Senthilkumar P, Subburam V (2001) Carbon from cassava peel, an agricultural waste, as an adsorbent in the removal of dyes and metal ions from aqueous solutions. Biores Technol 81:1-3

Ramos RL, Ovalle-Turrubiartes J, Sanchez-Castillo MA (1999) Adsorption of fluoride from aqueous solution on aluminum-impregnated carbon. Carbon 37:609-617

Rao VB, Mandava, Subba Rao M, Prasanthi V, Muppa R (2009) Characterization and defluoridation studies of activated Dolichos Lab Lab carbon. Rasayan J Chem 2(2):525-530

Reardon EJ, Wang Y (2000) A limestone reactor for fluoride removal from waste waters. Environ Sci Technol 34:3247-3253

Rozada F, Otero M, Garcia I (2005) Activated carbons from sewage sludge and discarded tyres, Production and optimization. J Hazard Mater 124(1-3):181-191

Saha S (1993) Treatment of aqueous effluent for fluoride removal. Water Res 27:1347-1350

Sai sathish R, Raju NSR, Raju GS, Nageswara Rao G, Anil Kumar K, Janardhana C (2007) Equilibrium and Kinetic Studies for Fluoride Adsorption from Water on Zirconium impregnated Coconut Shell Carbon. Sep Sci Technol 42:769-788 
Sairam Sundaram C, Viswanathan N, Meenakshi S (2009) Defluoridation of water using magnesia/chitosan composite. J Hazard Mater 163(2-3):618-624

Savinelli EA, Black AP (1958) Defluoridation of water with activated alumina. J Am Water Works Assoc 50:34-44

Sehn P (2008) Fluoride removal with extra low energy reverse osmosis membranes: three years of large scale field experience in Finland. Desalination 223:73-84

Shihabudheen MM, Atul KS, Ligy P (2006) Water Res 40:3497-3506

Shin S, Jang J, Yoon SH, Mochida I (1997) A study on the effect of heat treatment on functional groups of pitch based activated carbon fiber using FTIR. Carbon 35(12):1739-1743

Simons R (1993) Trace element removal from ash dam waters by nanofiltration and diffusion dialysis. Desalination 89:325-341

Singh G, Kumar B, Sen PK (1999) Removal of fluoride from spent pot liner leach ate using ion exchange. Water Environ Res 71:36-42

Sreenivasa Rao V, Somasekhara Rao K, Nageswara Rao M, Upasana Sinha B (2011) Studies on the surface characterisation of newly prepared activated Kaza's carbons. Asian J Biochem Pharmacol Res 2(1):567-584

Srimurali M, Pragathi A, Karthikeyan J (1998) A study on removal of fluoride from drinking water by adsorption onto low cost materials. Environ Pollut 99:285-289

Starsinic M, Taylor RL, Walker PL Jr, Painter PC (1983) FTIR Studies of Saran chars. Carbon 1(1):69-74

Susheela AK (2001) Treatise on Fluorosis, Fluorosis Research and Rural Development Foundation, India, Fluoride, vol 34., pp 181-183

Tor A (2007) Removal of fluoride from water using anion-exchange membrane under Donnan dialysis condition. J Hazard Mater 141:814-818

Tripathy SS, Bersillon J-L, Gopal K (2006) Removal of fluoride from drinking water by adsorption onto alum-impregnated activated alumina. Sep Purif Technol 50:310-317

Underwood EJ (1997) Trace Elements in Human and Animal Nutrition. Academic Press, New York, p 545

Venkata Mohan S, Ramanaiah SV, Rajkumar B, Sarma PN (2007) Removal of fluoride from aqueous phase by biosorption onto algal biosorbent Spirogyra Sp. I02: sorption mechanism elucidation. J Hazard Mater 141:465-474

Viswanathan N, Meenakshi S (2010) Enriched fluoride sorption using alumina/ chitosan composite. J Hazard Mater 178:226-232

Wang Y, Reardon EJ (2001) Activation and regeneration of a soil sorbent for defluoridation of drinking water. Appl Geochem 16:531-539

WHO (1984) Guidelines for drinking water quality. Health criteria and other supporting information. Geneva, Switzerland, vol 2

WHO (2004) Guidelines for Drinking Water Quality. World Health Organization, Geneva

Yadav AK, Kaushik CP, Haritash AK, Kansal A, Neetu R (2006) Defluoridation of drinking water using brick powder as an adsorbent. J Hazard Mater 128:289-293

Yang T, Lua A (2003) Characteristics of activated carbons prepared from pistachio-nut shells by physical activation. J Colloid Interface Sci 267:408-417

Yu C, Qiu JS, Sun YF, Li XH, Chen G, Zhao ZB (2008) Adsorption removal of thiophene and dibenzothiophene from oils with activated carbon as adsorbent: effect of surface chemistry. J Por Mater 15:151-157

Zawadzki J (1989) Chemistry and Physics of Carbon. Marcel Dekker, New York, pp 147-380

Zhang PC, Spark DL (1990) Kinetics and mechanisms of sulfate adsorption/ desorption on goethite using pressure-jump relaxation. Soil Sci Soc Am J 54:1266-1273

Zhuang QL, Kyotani T, Tomita A (1994) DRIFT and TK/TPD analyses of surface oxygen complexes formed during carbon gasification. Energy Fuels 8:714-718

\section{Submit your manuscript to a SpringerOpen ${ }^{\circ}$ journal and benefit from:}

- Convenient online submission

- Rigorous peer review

- Immediate publication on acceptance

- Open access: articles freely available online

- High visibility within the field

- Retaining the copyright to your article

Submit your next manuscript at $>$ springeropen.com 